Citation: Beal. C, Stewart, RA., Fielding, K. (2011) A novel mixed method smart metering approach to reconciling differences between perceived and actual residential end use water consumption. Journal of Cleaner Production, 2011, doi:10.1016/j.jclepro.2011.09.007.

\title{
A novel mixed method smart metering approach to reconciling differences between perceived and actual residential end use water consumption
}

\section{Authors:}

\section{Cara Beal $^{1}$ (corresponding author)}

${ }^{1}$ Research Fellow, Smart Water Research Centre, Griffith University, Gold Coast Campus, 4222 Australia, E-mail: c.beal@griffith.edu.au

\section{Rodney A. Stewart ${ }^{2}$}

${ }^{2}$ Director, Centre for Infrastructure Engineering \& Management, Griffith University, Gold Coast Campus, 4222, Australia, E-mail: r.stewart@griffith.edu.au

\section{Kelly Fielding ${ }^{3}$}

${ }^{3}$ Senior Research Fellow, Institute for Social Science Research, School of Psychology, University of Queensland, 4072 and Sustainable Ecosystems, CSIRO, Queensland Biosciences Precinct, St Lucia 4072 Australia, E-mail: Kelly.fielding@csiro.au 


\begin{abstract}
Studies have shown that householders' perceptions of their water use are often not well matched with their actual water use. There has been less research however, investigating whether this bias is related to specific categories of end use and/or specific types of sociodemographic and socio-psychological household profiles. A high resolution smart metering study producing a detailed end use event registry as well as psycho-social and sociodemographic surveys, stock inventory audits and self-reported water diaries was completed for 252 households located in South-east Queensland, Australia. The study examined the contributions of end uses to total water use for each group that self-identified as "low", “medium” or "high” water users. A series of univariate tests (i.e. analysis of variance) were conducted to examine a range of variables that characterise each self-identified water usage group including age, income, percentage of water efficient stock (e.g. low flow taps), family size and composition and water conservation intentions and attitudes. The level of information consumers receive on their water bill as well as the diurnal end use patterns were also examined. The paper concludes with a discussion of the general characteristics (i.e. income, age, gender and family composition) of groups that tended to overestimate or underestimate their water use and how this knowledge can be used to inform demand management policy such as targeted community education programmes and communitybased social marketing. Further, the potential for positive economic and sustainable development outcomes from this research is also discussed.
\end{abstract}

Keywords:, smart meters, residential water consumption, water use behaviour, water use beliefs

\title{
1. Introduction
}

\subsection{End use studies to inform water demand managers}

Water security remains one of Australia's greatest issues of concern as many urban and rural regions are facing a severe drought after years of continued lower than average rainfall. In 
2009, South-east Queensland (SEQ) emerged from one of its most harsh and protracted droughts on record. The variability of rainfall in the region, combined with high population growth and strong economic development, means that effective supply and demand side water management is critical. In an attempt to improve water security, many government authorities in Australia have imposed water restrictions and water saving measures to manage demand and ensure the conscious use of water across the residential, commercial and industrial sectors. Both in Australia and internationally, recent research suggests that attitudes and behaviour toward potable water supplies have changed due to greater social awareness and increasingly widespread exposure to drought conditions; people are beginning to genuinely value water as a precious resource (Jones et al. 2011, Jorgensen et al. 2009, Fielding et al. 2009). For example, the combination of state and local government rebate programmes for water efficient fixtures and rainwater tanks, and enforced water restrictions have resulted in a large reduction in household water use in SEQ (Beal et al 2011, Willis et al. 2010a, Queensland Water Commission [QWC] 2010). Internationally, the success of demand management strategies such as pricing, restrictions and water conservation education have been shown to have variable effects on changing the public perception on water consumption (Arbues et al. 2010, Olmstead and Stavins 2009, Nieswiadomy 1992)

The shift in public perception of water requires renewed understanding of the relationships between the end use and the end users of residential water. Furthermore, despite successful demand management outcomes, approaches by many regulating authorities to reduce water consumption are often reactionary rather than proactive (Farrelly and Brown 2011, Kennedy 2010, Rendwick and Archibald 1998). Although there are many examples of proactive water demand management approaches emerging (e.g. Domènech and Saurí 2011, Farelly and Brown 2011, Inman and Jeffrey 2006), the often reactionary policies to reduce water demand in a time of potential supply crisis highlights the need for more detailed information at the “coalface”. For example, information on how the water is proportioned in households and how this may change both spatially and temporally across any given region would provide good insight for demand managers about which local regions to target. To this end, Chang et al. (2010) examined spatial variations of residential water consumption in Oregon and conclude that such a dataset would greatly enhance the development of urban water policies in regions of limited water resources. Blokker et al. (2010) suggest that measuring end use data across seasons and regions is the foundation for water consumption predictions and the development of demand forecasting/water distribution network models. Similarly, Arbués et 
al (2003) and White and Fane (2002) emphasise the need for such basic building blocks in the creation of effective demand side management policy. Empirical end use data is essential for validating water use forecasting models such as presented by Blokker et al. (2010), Chu et al. (2009) and Druckman et al. (2008). Thus, the disaggregation of residential water end use is a critical first step in the development of relevant and successful water policy. A number of end use studies have been conducted both in Australia (e.g. Water Corporation 2011, Beal et al. 2011, Willis et al. 2011b, Willis et al. 2010a, Roberts 2005, Loh and Coghlan 2003) and internationally (e.g. Heinrich 2008, De Oreo et al. 1996).

Water consumption patterns and behaviours are highly varied amongst households due to the influencing factors of climate, socio-demographics, house size, family composition, water appliances, cultural and personal practices (Russell and Fielding 2010, Juárez-Nájera et al. 2010, Arbués et al 2003, Loh and Coghlan 2003). As the end use of water is influenced by a number of subjective or manual water use practices within a household (e.g. length of shower, height of bath and frequency of tap use), surveys or questionnaires are key components of any end use study. End use data in combination with such socio-demographic information can facilitate the identification of correlations between water behaviours and key demographical subsets within a population (e.g. income, age, gender and family composition).

\subsection{Social perspectives of water consumption and conservation behaviours}

Effective and relevant implementation of demand management and water conservation strategies is strongly underpinned by an understanding and knowledge of how consumers perceive and use their water (Jones et al. 2010, Jorgensen et al. 2009). There have been many studies that have identified the drivers of water consumption and conservation. Jorgensen et al. (2009) and Russel and Fielding (2010) both present detailed overviews of the literature in this field. Direct drivers include climate, household characteristics (e.g. size, composition, income), regulatory environment (e.g. rebates, incentives, restrictions), personal characteristics (e.g. intention and knowledge on water conservation) and property characteristics (e.g. garden size, pool, house age) (Jorgensen et al. 2009, Corral-Verdugo et al. 2006, Gregory and Di Leo 2003). Indirect drivers relate more to the personal characteristics (subjective norm, attitude), environmental and water conservation values, socio-economic status, and a sense of trust and fairness to institutions and other consumers 
(Russell and Fielding 2010, Jorgensen et al. 2009, Corral-Verdugo et al. 2002, Syme et al. 1990-1991).

In Australia, there is growing evidence to suggest that residential consumers' attitudes to water conservation have become more positive and this change in attitudes is paralleled by behavioural shifts in water use (Beal et al 2011, Willis et al. 2011b, Millock and Nauges 2010, Willis et al. 2010a). Despite the growing awareness of the need for water conservation amongst the public, studies have shown that householders' perceptions of their water use are often not well matched with their actual water use (Millock and Nuages 2010, CorralVerdugo and Frías-Armenta 2006, Hamilton 1985). The mismatch between water use perceptions and outcomes is one that echoes the low correspondence that is often found between attitudes and behaviour (Kraus, 1995, see also Dolnicar \& Hurlimann, 2010). Kantola et al. (1984), for example, showed that peoples' self-reported attitudes toward energy conservation and their actual energy consumption differed and observed that people reduce the dissonance between attitudes and behaviour by bolstering or reaffirming their initial attitude (Kantola et al. 1984). Others describe the differences between beliefs and actual behaviour as more of a conflict between good intentions and difficulties in actually acting on them (Anker-Nilssen 2003).

In the context of household water use, there are a small number of studies reporting on perceived and actual water consumption. Hamilton (1985) observed that self-reported water consumption was not an accurate method of determining residential water use. The disparity between believed and actual water use was influenced by socio-economic status and conservation behaviours, where people from higher income categories and people who were 'conservation aware' tended to more accurately estimate their water use (Hamilton 1985). Syme et al. (1990-1991) explored the relationship between householder attitudes and actual water consumption in Perth, Australia. They found, during drought-free conditions, that external water use and associated attitudes to the investment and recreational assets of gardens were important consumption predictors. A key conclusion from this work was the need for water policy to consider consumer attitudes to garden water use and upkeep (Syme et al. 1990-1991). Aitken et al. (1994) found that attitudes, habits and values were poor predictors of water use and hence did not support the relationship of water use attitudes to actual behaviour (i.e. water consumption). Building on this, Aitken et al. (1994) identified a number of homes in a dissonant situation, and conducted a second study to explore whether 
this dissonance between perceptions and actual water use would be reduced with interventions such as feedback of the household's actual water consumption. As a result of this feedback, there was a significant convergence between perceived water conservation and actual water consumption. Using a combination of water billing records and survey responses, De Oliver (1999) examined water consumption following voluntary and mandatory water restrictions and investigated whether consumption reductions, if any, were influenced by socio-demographic variables such as family composition and income. The results demonstrated a substantial disconnect between survey responses and manifested actions, of which the latter were influenced in differing degrees by income, political persuasion, ethnicity, home ownership and education. Gregory and Di Leo (2003) matched averaged household annual billing records with a household survey designed to elicit information on the habits, attitudes, awareness and contextual factors to explore relationships between water conservation and consumption and psychological drivers. They found that lower water users (using a benchmark of a council free allowance water usage rate) tended to be older, less educated and of lower income than the higher water users (Gregory \& Di Leo 2003). The authors concluded that attitudes to water usage appeared to be poor predictors of actual water consumption behaviour.

Although the above studies compared actual water consumption with perceived or intended water use, they did not specifically measure residential end uses and thus could not identify which water consumption activities may be contributing to these disparities. O'Toole et al. (2009) conducted a study using two self-reporting approaches to examine residential water end use activity; however, the self-reports were not matched with actual water consumption. Despite the growing number of water end use studies both in Australia (e.g. Water Corporation 2011, Willis et al. 2011b, Beal et al 2011, Roberts 2005, Loh and Coghlan 2003) and internationally (e.g. Fidar et al. 2010, Heinrich 2008, De Oreo 1996), there has been no reported examination of perceived versus actual water consumption using domestic water end use data. A considerable knowledge gap therefore remains on the role that residential water end uses such as showers, clothes washers, taps and toilets play in the water bias phenomenon discussed above. Syme et al. (2004), in their paper on predicting and understanding external water use, conclude that there is a need for specific and accurate attitudinal and water use measurements to fully assess behavioural influences on water use. The advent of high resolution smart water metering technologies enables the disaggregation 
of flow data into individual water end use events, thereby significantly enhancing the current level of understanding of domestic water use (Stewart et al. 2010).

\subsection{Research aims}

The main aims of this study are to:

1. compare actual versus believed water consumption across a sample of households in SEQ to assess whether perceived water consumption matches actual water consumption;

2. identify which residential end uses and water efficient stock contribute to any disparities between perceived and actual water consumption;

3. explore psycho-social variables that may contribute to any disparities between perceived and actual water consumption; and

4. describe general characteristics of groups that may overestimate and underestimate their water use.

The knowledge from this study allows a demographic, psycho-social and end use profile to be developed of groups who may over- or under-estimate their water use. The combination of these different types of data allows the study to make important empirical contributions to the literature in this area. Moreover, the findings can help inform demand management policy such as targeted community education programmes.

\section{Methods}

\subsection{South East Queensland Residential End Use Study}

The data for the current study is generated from the South East Queensland Residential End Use Study (SEQREUS) and a water use survey conducted within the Demand Management and Communication project, both funded through the Urban Water Security Research Alliance. Households from four local authority boundaries located in the south east corner of Queensland, Australia, took part in a water use survey $(\mathrm{N}=1750)$. Participants for the 
SEQREUS study ( $n=252$ ) were selected from the larger pool of survey participants who consented to be contacted to take part in future research.

A mixed method, advanced water end use measurement approach was followed in order to obtain and analyse water use data. This incorporated physical measurement of water use via smart meters with subsequent remote transfer of high resolution data and documentation of water use appliances and behaviours. The mixed method approach, while often more costly and time consuming, maximises the likelihood of obtaining a high level of sophistication in the accuracy and quality of the final dataset. The relationship between smart metering equipment, household stock inventory surveys and flow trace analysis is shown in Figure 1. Responses from the household water use survey were used to investigate the psycho-social variables of water consumption.

Upon completion of recruitment, standard council residential water meters were replaced with modified Actaris CTS-5 water meters. These 'smart' meters measure flow to a resolution of 72 pulses/L or a pulse every $0.014 \mathrm{~L}$. The smart meters were connected to Aegis Data Cell series R-CZ21002 data loggers. The loggers were programmed to record pulse counts at five second intervals. Data was wirelessly transferred to a central computer and stored in a database for subsequent analysis (Figure 1). A representative sample of received data was extracted from the database and disaggregated into all end use events associated with the sampled residential households using the Trace Wizard ${ }^{\circledR}$ software (Aquacraft 2010).

Concomitantly with meter and logger installation, a water fixture/appliance stock survey was conducted at each participating home in order to investigate how householders interact with such stock. By completing the stock survey, the householder provided information on typical flow rates of taps and showers, the number and degree of water-efficient appliances and the typical water consumption behaviours of the householders. In addition to the stock survey, each household was asked to complete a water diary where as many internal and external water use events as possible were recorded over a 7 day period. This facilitated the disaggregation of trace flows from each home and also provided a valuable snapshot of the daily water consumption habits within each home. A detailed discussion on the research methods is provided in Beal et al. (2010).

Insert Figure 1. 


\subsection{Household water use survey procedure}

In total, 1985 residents (note that for some households, multiple responses were sought and received) of SEQ completed the Household Water Use Survey. The aim of the survey was to capture attitudes and behaviours toward household water conservation. The Household Water Use Survey consisted of 27 multi-item questions (totalling 103 items) which were designed to elicit information from participants about various aspects of household water use and conservation, as well as standard demographic and household composition data. The majority of questions used 7-point Likert Scales, with some open-ended and categorical multi-choice questions also included. Participants were asked questions about curtailment behaviours, that is, their intentions and attitudes toward everyday water saving behaviours and the extent to which they engaged in these behaviours. They were also asked about efficiency behaviours, that is, their intentions and attitudes toward installing water efficient appliances and whether they currently had installed these appliances. Other variables included self identification as a water conserver and the extent to which the household valued and were committed to water conservation.

In the last stage of the survey, respondents were asked directly about their household water consumption. Firstly, respondents were asked to write down their average daily water use (litres per household) provided in their latest household rates notice. Immediately following this the respondents were asked "Do you think that your household is a high, medium or low water user?”, with an option for "Don’t know”. This question is the focus of this study. The question related to overall water use of the household. In practice, at the time of the survey, outside water use was negligible because of restrictions, rainfall and/or modified behaviours towards outdoor water use. All survey responses were collated in a database along with the winter end use data for each home. The final database provided a comprehensive repository of end use data and matching socio-demographic data and socio-psychological responses to water consumption and conservation. This is the first known study of its type to measure such a range of variables. A detailed discussion on the research methods for the Household Water Use Survey is provided in Spinks et al. (forthcoming).

\subsection{Analysis}


A two week continuous period of data from each household was analysed by Trace Wizard ${ }^{\circledR}$ software version 4.1 (Aquacraft 2010). This software allows flow traces to be identified for each major household end use: toilet, washing machine, taps, showers and bathtubs, dishwasher, irrigation and leaks. Water diaries and stock appliance audits were used by the analyst to help identify flow trace patterns for each household. The data collection period was between June $14^{\text {th }}$ and June $28^{\text {th }}$ ，2010. This was the winter two week period which represented the winter household water use for the SEQREUS, from which the data for this study was sourced. Note that seasonal data was not available at the time of this study, although it is envisaged that future extensions to this work will incorporate a longitudinal study covering at least one full season of data. Once a template was created for each household, data for the two week period $14^{\text {th }}$ to $28^{\text {th }}$ June 2010 was analysed. Summary data for each water event was then calculated including duration, volume and peak flow rate. Importantly, the software also has the capability to distinguish between two simultaneous events. On completion of trace flow analysis and disaggregation of end uses, a database registry of end use event information was generated for each home.

A series of one-way analyses of variances (ANOVA) were also conducted to compare the high, medium and low water use groups on a range of psycho-social variables. Levene's test for equal variances were checked and showed that the variances of the populations from each sample were equal. The means from each self-report group were tested using the t-statistic at ${ }^{*} p<0.05$, ${ }^{* *} p<0.01$ and ${ }^{* * *} p<0.001$. This three star criteria allows the identification of the relationships that are strongly significant (i.e. $p>0.01$ ) and thus are less likely to be affected by an inflated Type 1 error, of which can occur with multiple univariate analyses (Keselman et al. 1998). Nonetheless, $p<0.05$ cut-off values representing moderate significance have been also reported given the nature of expensive high resolution smart metering studies and the resource intensive end use disaggregation process limiting the recruitment of larger sample sizes. Analysis of covariance (ANCOVA) were performed to control for any treatment effects of household income and education on the outcome. Where a significant difference in means was reported, post hoc analysis was carried out using the Tukey HSD test. This identified which means differed significantly from each other. The analysis are based on both per person and per household water consumption data. Note that although the per person data takes into account household size, it is unlikely that the relationship between water use and household size is strictly linear. To further check for household size, analyses were also conducted for each household size cluster, where the same trends were observed between 
each self-reported water usage group. That is, the group self-reporting as medium water users used more water than the group self-reporting as high water users, regardless of household size cluster.

\section{Results and Discussion}

\subsection{Actual versus perceived household water consumption}

A total of 222 homes were able to be paired with measured end use consumption and matching survey responses. The sample sizes for each self-reporting group were 94 'high' water users, 90 'medium' water users and 21 'low' water users. Interestingly, only a small number of households (less than $10 \%$ of the sample) self-reported as low water users. This is perhaps surprising given that people often self-report in socially desirable ways, even if that does not match their behaviour (Corral-Verdugo and Frías-Armenta 2006, De Oliver 1999). Unfortunately, this unexpectedly small sample size for the 'low' water use cluster increased the confidence intervals within the sample, and hence reduces the likelihood of statistically significant observations. Nevertheless, some general trends were observed for this group.

From the SEQREUS, the overall average water use was 370.7 litres per household per day $(\mathrm{L} / \mathrm{hh} / \mathrm{d})$ which equated to an average consumption of 145.3 Litres per person per day $(\mathrm{L} / \mathrm{p} / \mathrm{d})$ (Figure 2).

\section{Insert Figure 2}

One way ANOVAs were conducted on end use variables obtained from the trace analysis and, socio-demographic and psycho-social variables obtained from the household water use survey which was concerned with water conservation actions, attitudes and beliefs. When controlling for household income and education using ANCOVAs, remained significant. Post hoc comparisons using the Tukey HSD test were performed to identify which of the perceived water use groups were driving any significant differences identified from the ANCOVAs. 
In terms of perceived water use clusters, a clear pattern emerged from the results which showed that self-reported high water users, although not statistically different, typically consumed less $(130 \mathrm{~L} / \mathrm{p} / \mathrm{d})$ than both the self reported medium $(156 \mathrm{~L} / \mathrm{p} / \mathrm{d})$ and low (143 $\mathrm{L} / \mathrm{p} / \mathrm{d}$ ) water users on a per capita basis (Figure 3a). The remaining respondents who answered 'don't know' ( $n=17$ ) had an average water use of $132 \mathrm{~L} / \mathrm{p} / \mathrm{d}$. The difference between self-reported water use groups emerges even more clearly when analysing on a per household basis (Figure 3b). The mean of perceived high water users (301 L/hh/d) was significantly lower than the mean consumption for perceived medium water users (452 $\mathrm{L} / \mathrm{hh} / \mathrm{d})(F[2,203]=6.19, p<0.01)$. The end uses that were associated with the increased water use for self-reported medium and low water users were predominantly taps, shower and clothes washer. These end uses commonly comprise the bulk of total household water use (Beal et al. 2011, Willis et al. 2010b, Roberts 2005) and have been shown to be consistently associated with elevated household water usage (Willis et al. (in review), Water Corporation 2011, Gregory and Di Leo 2003, Aitken et al. 1994).

These data suggest that self-identified medium water users generally underestimated their shower, tap, and clothes washer use. Per capita shower use was significantly greater $(F[2,203]=6.53, p<0.01)$ in the perceived medium water use group compared with the perceived high water users (Figure 3a). Again, this was stronger on a per household basis where tap $(F[2,203]=4.72, p<0.01)$, dishwasher $(F[2,203]=3.19, p<0.05)$, shower $(F[2,203]$ $=6.69, \mathrm{p}<0.001)$, and clothes washer $(F[2,203]=4.65, p<0.01)$ were all significantly higher in the perceived medium water user group compared with the perceived high water user group (Figure 3b). A reason for the differences between perceived medium and perceived high water users may be partially attributable to the lack of knowledge of the respondent about how water is proportioned around the house beyond their own use (O’Toole et al.

\section{Insert Figure 3}

2009). For example, the cumulative and non-automated nature of tap use may make this end use quite easy to underestimate, especially on a household basis. Additionally, taps are readily accessible to young children and are often sources of leaks. O’Toole et al. (2009) noted that an individual response to a collective consumption behaviour (e.g. judgement of 
level of household water use) is potentially erroneous, particularly so for end uses that the survey respondent is less exposed to.

Leakage rates were the greatest for the respondents who 'didn't know' suggesting that they may have been aware of a leak but not sure of its contribution to their total household water consumption (Figure 3).

\subsection{Socio-demographic trends}

The socio-demographic characteristics of each self-reported water use group is presented in Table 1. In the following sections "don't know” respondents are excluded from the analyses as the focus is on understanding the perceived degree of water use rather than the presence of absence of knowledge of water use. The variables examined were respondent characteristics, household socio-demographics, and household water efficient stock. The age of respondents who perceived their household to be high water users was significantly higher $(p<0.001)$ with a mean of 57 years than the perceived medium water user group who had a mean of 47 years.

In terms of household composition, the total number of people and number of children per house were both significantly lower $(p<0.001)$ for perceived high water users compared to medium users (Table 1). Additionally, the number of young children ( $\leq 3$ years old) was also significantly lower $(p<0.05)$ for perceived high water users compared with medium water users. Larger families and families with children are generally accepted to use more water in terms of per household volume (Russell and Fielding 2010, Arbués et al. 2003). The data presented in Table 2 demonstrates that there may be a lack of knowledge of how and when children are using the household water, resulting in a tendency to underestimate the contribution of children in household water demand. This is supported by the high number of children, their greater age and the percentage of teenagers for the respondents of medium or low perceived household usage (Table 1). Wutich (2009) and O’Toole et al. (2009) also found larger families were more likely to erroneously estimate their water use compared with smaller families. 
Household income is typically shown to be associated with higher income families consuming more water (Domènech and Saurí 2011, Gregory and Di Leo 2003, De Oliver 1999). This is also observed in this study: self-reported high water users (who used the least water on average) had a significantly lower $(p<0.001)$ household income than the other respondents (Table 1$)$.

In general, results in Table 1 suggest that the group who used lower than average water consumption, but believed they were high water users tended to be older (respondent), have smaller families with fewer children, and have a lower household annual income than the self- reported medium and high (who had above study average water use) water users.

\subsection{Gender and education trends with water use perceptions}

The gender ratio across the three water use categories was similar, and consistent with this chi-square analyses showed that there was no significant difference in the number of males and female respondents who completed the survey across the three groups $(2,1.744, p>0.05)$ There were also no significant differences $(p>0.05)$ in per capita water or per household consumption between male and female respondents for any self-reported group. Inspection of the education ratios in Table 1 demonstrated higher education levels in the self-identified medium and low water use groups than the high water use group, suggesting increased water consumption in households where the respondents had a higher level of education (Table 1). The level of education of respondents was investigated further (Figure 4) as it has been shown to be positively correlated with lower water consumption and higher water conservation behaviours (Millock and Nuage 2010, Barrett and Wallace 2009, Gilg and Barr 2006). Respondents were grouped into three different clusters: secondary, which represented respondents who had reached a level of primary or secondary education; Trade/TAFE, which represented to people who had a trade (e.g. electrician / plumber) or had attended a TAFE (trade and further education) institute; and tertiary, which represented people who had a university degree or higher. In general, a trend towards the medium self-reported groups using more water on average than high self-reported groups emerged in the two lower education categories as the survey respondents who perceived a high water actually used less $(\mathrm{p}<0.05)$ water $(\mathrm{L} / \mathrm{hh} /$ day) than the perceived medium water users. This trend did not emerge for the tertiary educated respondents as there were no significant differences $(p>0.05)$ between water use among the three water self-reporting groups for either per capita or per household water consumption. Shower consumption $(\mathrm{L} / \mathrm{hh} / \mathrm{d})$ was significantly higher 
$(p<0.01)$ for the perceived medium water users than the perceived low water users (Figure 4b)

\section{Insert Figure 4.}

\subsection{Household water appliance/fixture stock and perceived water use}

In terms of water efficient appliances and fixtures there were some general trends for people who identified as medium and low water users to have higher star rated and water efficient clothes washers and lower flow rated shower heads than those who identified as higher water users even though the medium and low water use groups used more water than the high water users (Table 2). There were no significant differences $(p>0.05)$ between any self-nominated user groups and either the star rating of the water efficient washing machines or shower flow rates. The water use groups differed though on the volume of water used in washing machines installed in that the perceived medium water user group was significantly higher $(p<0.05)$, than the perceived high water user group. The peak shower flow rate was also significantly lower $(p<0.05)$ for perceived high water users compared with perceived low water users (Figure 5).

In general the results in Figure 5 show a trend for the self-nominated medium and low water users (i.e. higher average income earners as shown in Table 1) to have more water efficient appliances (i.e. higher star rated washing machines) and fixtures (i.e. low flow rated shower heads). Consistent with this, research shows that households with higher incomes have a greater tendency to install such water efficient technology (Millock and Nuages 2010, Olmsetad and Stavins 2009, Gregory and Di Leo 2003).

\section{Insert Figure 5.}

It is also suggests that these higher income homes are not necessarily lower water consumers, particularly on a per household basis. For example, Olmstead and Stavins (2009) postulate that the water savings benefit from water efficient appliances can be offset by behavioural changes prompted by the technology. For example, people may take longer showers if they have installed a low-flow shower head (Mayer et al. 1998). Alternatively, the presence of water conserving technology may not be enough to alter a user's behaviour, as reported by 
Willis et al. (2010a) who observed that some people continued to have very high volume showers, despite the presence of a recently installed shower alarm. A subsequent longitudinal study by Stewart et al. (2011) provides evidence that alarming visual display showering monitors did not instil a sustained showering behaviour change over the longer term, since householders often reverted to previous habits. Kappel and Grechenig (2009) also found this to be case in their study of consumption behaviour changes resulting from the installation of visual usage display unit in showers. Finally, Syme et al. (2000) noted that people with water efficient appliances are not necessarily effective in saving water elsewhere in the house.

The finding that installing water efficient technologies does not always translate to lower water consumption could be explained in part by differing drivers of water use behaviours. Gardner and Stern (1996) describe curtailment and efficiency behaviours as the two main ways that people can conserve water. Efficiency behaviours are associated with the installation of water-efficient technology such as low flow taps and shower heads, high star rated washing machines and rainwater tanks. Curtailment behaviours are associated with resource conservation rather than technology such as ensuring a full load in dishwasher or clothes washer, turning the taps off during shaving and teeth brushing and so on. The drivers of these behaviours have been shown to be affected by socio-economic factors (Russell and Fielding, 2010, Millock and Nuages 2010). The results of the current study indicate a trend such that higher income, larger, younger and more educated households tend to install efficiency appliances which may not always be sufficient in reducing water consumption if curtailment actions are not present. Using the same reasoning it could also be argued that lower income earners in older, smaller and less educated households tend towards curtailment behaviours of water use frugality rather than adoption of potentially expensive and potentially superfluous (i.e. if a one household family) technology. Gregory and Di Leo (2009) and Gilg and Barr (2006) also reported a similar profile of low water users who were older, less educated, had lower incomes and smaller household sizes.

\subsection{Diurnal patterns of underestimated water end uses}

Average daily demand end use diurnal patterns can be used to characterise average patterns of water use throughout a 24 hour period for a range of chosen variables. End use diurnal patterns (represented in 24:00 time) were generated for each self-reported water use group, only considering those end uses (i.e. shower, clothes washer, tap and toilet) identified as 
contributing to the disparity between perceived and actual water consumption (Figure 6). These graphs provide a representation on the average day and hour flow rates (on a per capita basis) for the households in each self-reported group. The average peak (and low) periods of water demand can be determined on a real-time basis, providing valuable information on average daily volumes and frequencies of end uses and thus the typical water consumption behaviours of each self-reported water user group.

When comparing diurnal patterns between self-reported high, medium and low water users, a number of observations may be made. Firstly, the average diurnal pattern for 'high' water users (in fact the low water users) shows two distinct consumption peaks at around 9.00am and between 6 and 7.00pm (Figure 6a). The main contributors to these peaks are shower (particularly evening) and clothes washer (particularly morning).

\section{Insert Figure 6.}

In contrast, the 'medium' water users (Figure 6b) and to a lesser extent the 'low' water users (Figure 6c), exhibit a double peak water use in the morning occurring across a longer time period (7.00am to $11.00 \mathrm{am})$. Additionally, water use from clothes washers in particular occurs to a greater extent throughout the day and the evening peak period is more prolonged than self-reported high water users. This double peak in the morning may be a result of two distinct water users, for example one resident may be leaving for work and showering earlier, while a second resident engages in shower and clothes washing later on in the morning. Householders are not necessarily aware of others engaging in high end use activity throughout the day and thus this high use may be unknown by the survey respondent (O’Toole et al. 2009). Remembering that household shower and clothes washer use was significantly higher for self- reported medium users, this second morning and evening peak, potentially unknown to the respondent, may be contributing to this variance. Clothes washing and general tap use was also shown to be poorly recalled end uses from respondents involved in both diary and prompted recall methods in a study by Wutich (2009). O’Toole et al. (2009) observed the frequency of clothes washing and toilet use from other household occupants to be the most poorly understood by the survey respondent. Aitken et al. (1994) also found a correlation between frequency of clothes washing and incorrect prediction of water consumption. These previous findings provide further evidence that high end use activities are associated with over or underestimation of total household water consumption. 


\subsection{Attitudes and beliefs of respondents}

Examination of end uses have revealed self-nominated high water users to overestimate the actual water use largely in the activities of showering, clothes washing and tap use. Less so, although with marked consistency, self-nominated low water users have underestimated their water use usually for the same high volume end uses. Additionally, an examination of sociodemographical characteristics highlighted some general profiles of people who tend to overestimate and underestimate their water use. Hamilton (1985) concluded that the errors he observed from under-reporting water use could be attributed to the respondents' desire to give socially acceptable answers. One further explanation for the over-reporting of water use by the self-nominated high water users is the expectations that this group have of their own water use. To explore this, analyses are conducted comparing the three groups on a range of psycho-social variables to assess whether self-reported high water users are more likely to have stronger water conservation intentions or beliefs.

One way ANOVAs were conducted on variables from the household water use survey which was concerned with water conservation actions, attitudes and beliefs (Table 2). There were significant differences ( $p<0.05$ or lower) between the self-reported water use groups on 7 of the 11 variables examined (Table 2). Post hoc comparisons using the Tukey HSD test were performed to identify which of the perceived water use groups were driving these differences.

\section{Insert Table 2.}

Self-nominated high water users were significantly $(\mathrm{p}<0.01)$ more likely than medium and low water users to see themselves as a water conserving household. The same pattern emerged on self-identity (i.e., the extent to which the survey respondents perceives him or herself as a water conserver): the survey respondent who self-nominated as a high water user think of themselves significantly more $(p<0.05)$ as a water conserver than self-nominated medium water users. Perceived low water users to have a significantly lower $(p<0.05)$ personal obligation to save water around the house compared with medium, and high selfnominated water users (Table 2). 
Analyses of past behaviours show that people who self-nominated as high water users report significantly $(p<0.01)$ more often having shorter showers relative to medium water users. , and reported significantly more $(p<0.05)$ often being water-wise in the kitchen relative to self-nominated low water users. There was also a tendency for self-reported high water more than medium or low water users to believe that water conservation was important in their household (Table 2). Although there was no significant differences $(p>0.05)$ in the means of the perceived water user group for the question "it is expected of me that I should install water efficient appliances”, the data suggests a trend for the more committed water conservers to over-estimate their water use. These people may be setting themselves a higher benchmark on what is low or personally acceptable consumption and believe there is always something more they could do to reduce their household's consumption. This, together with the single, sharp diurnal peaks for high water end uses and evidence of curtailment rather than efficiency driven water conservation behaviours would suggest that the self-nominated high water users are more aware of their water consumption. This evidence potentially explains a significant proportion of the disparity between perceived and actual water use.

Conversely, the self-nominated medium and low water users, who are less committed to water conservation, may also be less aware of their water consumption, as they are associated more with larger families with more children, double peaks in their diurnal patterns of use and adoption of more water-efficient technology. Aitken et al. (1994) argued that habitual and unthinking water use activities such as clothes washing and tap use are associated with unreasoned decisions. Furthermore, the frequent and repetitive nature of clothes washing, tap use and showers can reduce cognition and hence awareness of water use (Gregory and Di Leo 2003, Aitken 1994). Gregory and Di Leo (2003) suggest that habits or unreasoned influences may go some way to explaining the disparity between water consumption attitudes and actual water consumption.

\subsection{Relationship between water billing notice information and perceived water use}

Finally, we explored whether level of awareness gained from billing data may contribute to the mismatch between perceptions and actual water use. That is, did the respondents billing notice make them sufficiently aware of some form of 'norm' water consumption level that they could use as a reference for measuring their own consumption? In SEQ, a household billing notice or water account includes some level of information about the current water consumption of the household compared to a reference point. A brief description of the 
different levels of information for each of the four regions examined in the SEQREUS is presented in Table 3. Three of the four regions had a similar 'standard' level of information displayed on water accounts, with one region (i.e. Brisbane) providing much more detailed information on water use. Readers should note that the information level classifications 'standard' and 'high' used herein is not an official national standard but purely a reference for the current study comparisons. The mean actual consumption for the two classified billing notice information levels is shown for self-reported high, medium and low water users in Figure 7.

\section{Insert Table 3}

In terms of per capita water use, Brisbane respondents, who received the highest level of information about their water consumption, were the most accurate in estimating their water use (Figure 7a). The other three regions where a standard level of information was provided to the respondents via their water account were less accurate. This pattern was not evident when looking at household water use, although there was still a lower degree of disparity between perceived and actual water use for the Brisbane respondents whom received a high level of information on their account.

\section{Insert Figure 7}

These results suggest that receiving better comparison information about water consumption levels puts householders in a better position to a) know how much they may be consuming and b) know how to better manage their consumption (Willis et al. 2010a, Desmedt et al. 2009, Bartiaux 2008, Agthe et al. 1998, Aitken et al. 1994). Results presented here are consistent with this when analysed on a per capita basis. The reason for inaccuracies in estimating the water consumption on a per household basis may be attributed to the factors discussed earlier including a limited awareness of others householders' specific end use activities. Geyer-Allély and Zacarias-Farah (2003) list a number of approaches to facilitate sustainable household consumption. They point out that policies should aim to assist householders in making daily decisions about their consumption. In terms of the mismatch between perceived and actual water use this is an important point. Awareness, education and 
intervention strategies designed to increase the awareness of water consumption such as detailed information on water bills may be such an approach (Bartiaux 2008). This may be particularly relevant to those groups that may be misperceiving or under estimating their household use.

\section{General discussion and policy implications}

This paper used a combination of measured water consumption end use data and results from a detailed psycho-social questionnaire to ascertain any mismatches between perceived and actual water consumption. The targeted communities ranged from 1 person households to 5 person households and included a range of income, education and family compositions.

\subsection{Comments on general characteristics of perceived water use groups}

The results presented in this paper confirm the findings of other studies that perceived water consumption, or perceived water conservation, is not well matched with actual water consumption. In the current study, respondents who self-reported as medium water users consumed more water, particularly on a per household basis, than self-reported high water users. Moreover, the disparity between perceived and actual water use held across gender, education and socio-demographic groups. The general characteristics of the group of people that tended to overestimate their water use were: lower incomes and levels of education; less children; small household occupancies; and less likely to have water efficient technology. They were also more inclined to see themselves as water saving households and have greater intentions to save water around the house. Conversely, the characteristics of the group who underestimated their water use were: higher incomes; larger families with young children; and more likely to have more water efficient technology including low flow shower roses and higher star rated washing machines. This group tended to have lower self-identity as water conservers and demonstrated lower intentions to save water around the home. The ways in which this knowledge can inform future water demand management approaches can be grouped into soft or voluntary approaches where citizens are given the choice through education, awareness, incentives, etc., to change their consumption behaviours, or hard polices where mandatory tools such as restrictions are used to reduce demand (Jones et al. 2009).

\section{3. 'Soft' versus mandatory water policy tools}


The data presented in this paper suggests that households who have high incomes and water efficient appliance/fixture stock perceive lower overall use of water. This may result in these households being less concerned about behaviourally influenced end uses such as showering and taps, thereby pushing their overall consumption higher. Following on from this, family size and composition, rather than the technology, may be the greater factor in determining household water demand. That is; you can have good technology but you also need to match this with water conserving behaviour for non-automated water fixtures (e.g. shower and taps). Therefore the development of an approach which appeals to the curtailment of water use in these populations would yield more reliable water savings over the longer term. Ideally, this approach would be combined with strategies to identify and break water consumption habits pertaining to the high volume end uses such as showers, clothes washers and taps. Community-based social marketing (CBSM) may offer such a tool as it has been shown to affect actual attitudinal and behavioural change by taking an interactive approach (Kennedy 2010). An example of CBSM relating to water conservation may include monetary incentives for consumption reduction, prompts to remind people to engage in activities they might otherwise forget (e.g. turning taps off when brushing teeth, "is your clothes wash a full load”?) and the marketing of social norms such as provision of normative information on water conservation targeting specific family typologies.

Knowledge and feedback on actual consumption has been identified as an important factor influencing water consumption behaviour (Syme et al. 2000, Aitken et al. 1994). The lack of feedback or education and awareness of how water is being used in the house may also be a factor in water use perceptions not matching water use behaviour. Therefore, ensuring that consumers are well-informed on their water use relative not only to their previous use, but to their region or a similar demographic to them is critical in challenging the attitudes and behaviours of (unaware) high water users. The introduction of residential water bills in Australia that provide comparison information and benchmark water use to other households of the same size demonstrates that water utilities and government agencies recognise the importance of this type of information.

The over- or underestimation of water use by householders demonstrates that there cannot be exclusive reliance on individual household attitudes and beliefs to reduce water consumption. In some cases water demand management policy cannot rely solely on individual household attitudes and beliefs to reduce water consumption. Mandatory or hard measures such as water 
restrictions or tariff restructure are possibly more reliable in reducing residential demand, although a combination of regulation, efficiency appliances and behaviour change is likely to result in the best outcomes (Jones et al. 2009, Kenney et al. 2008, Renwick and Archibald, 1998).

\subsection{Sustainable development}

Adopting such policies or approaches discussed above will greatly enhance the awareness to the consumer of how much water they are actually using and how this can translate into both environmental and economically positive outcomes. There are a growing number of studies that describe the concept of water foot-printing, which is a strategic planning tool for sustainable urban (and regional) water management (e.g. Stoeglehner et al. 2011, Ridoutt and Pfister 2010). Baumgartner (2011) summarises some key factors that are required for the promotion and advancement of such sustainable development research, of which generating empirical evidence in the field of water consumption and behaviours as reported in this study lies well within.

\section{Limitations of study}

There are some limitations to this study that should be acknowledged. While general profiles can be made of the types of people who have overestimated their water use (i.e. the perceived high user group), the small sample size of the self-nominated low water group limits the generalisations that can made about people who are likely to underestimate their water use. Future research is needed with a wider study sample (of self-nominated 'low' water user households in particular) to explore the profile of low water users. The data has been analysed based on an individual survey respondent rather than a compilation of all householders responses (i.e. perceived water use level established from an average of all householders responses). This was a predetermined limitation at study inception as it was not feasible within the study scope to establish a true collective measurement on household beliefs, attitudes and perceptions; nonetheless some similarity of attitudes among family members can be assumed and there were questions that tapped perceptions of household attitudes to water conservation. Finally, the study examines one two-week end use data read snapshot. Ideally, such comparisons should be made across a range of seasonal periods. While indoor uses are largely not impacted by seasons, outdoor use is highly related to 
environmental conditions (e.g. temperature, rainfall, humidity). Collecting such seasonal end use data sets is a key objective of future research.

\section{Conclusions}

The hypothesis that perceived water consumption will differ from actual water consumption in a sample of 222 residential homes in South-east Queensland was tested using measured high resolution end use data and responses from a comprehensive household water use survey. Analysis of actual water consumption with matched self-reported water use, was conducted using multiple univariate tests (ANOVAs) with a three star significance criteria. Results suggested that this hypothesis was generally accepted at the 95\% confidence interval where self-nominated high water users consistently used less water than self-nominated medium and low water users. Frequent and high volume water end uses such as clothes washing, showering and tap use were associated with the incorrect estimations of household consumption. Households that overestimate or underestimate their water use also differ in their socio-demographic and psycho-social profile, providing further clues for why the disparity between perceived and actual behaviour arises. This type of profiling can be used to formulate targeted water policy approaches such as educating citizens on their water use through feedback information and community-based social marketing. Heightened feedback to consumers on their households' water consumption will improve their awareness and understanding of water use and help to encourage future water conservation behaviours. Thus the nature of this research has potential for positive economical and sustainable outcomes. Future research examining a larger sample size, across various seasons, may confirm the conclusion that people who underestimate their water use may be genuinely unaware of their high water use (e.g. habits), and/or are less water conservation minded.

\section{Acknowledgements}

This research was undertaken as part of the South East Queensland Urban Water Security Research Alliance, http://www.urbanwateralliance.org.au/. Particular thanks go to Allconnex Water, Queensland Urban Utilities, Unity Water, Anneliese Spinks (CSIRO), Sally Russell (Griffith University) and finally the SEQREUS research team at the Smart Water Research Centre. 


\section{References}

Agthe, D., Billings, B., Dworkin,. J., 1988. Effects of rate structure knowledge on household water use. Water Resources Bulletin 24(3), 627-630.

Anker-Nilssen, P., 2003. Household energy use and the environment--a conflicting issue. Applied Energy, 76(1-3), 189-196.

Aitken, C., McMahon, T., Wearing, A., Finlayson, B., 1994. Residential water use: predicting and reducing consumption. Applied Psychology 24(2), 136-158.

Arbues, F., Villanua, I. and Barberan, R., 2010. Household size and residential water demand: an empirical approach. The Australian Journal of Agricultural and Resource Economics 54, 61-80.

Arbues, F., Garcia-Valinas, M., Martinez-Espineira, R., 2003. Estimation of residential water demand: a state-of-the-art review. Journal of Socio-Economics 32, 81-102.

Aquacraft, 2010. Trace Wizard ${ }^{\circledR}$ software version 4.1, 1995-2010. Aquacraft, Inc. Boulder, CO, USA. $\leq$ http://www.aquacraft.com/>

Bartiaux, F., 2008. Does environmental information overcome practice compartmentalisation? Journal of Cleaner Production 16, 1170-1180.

Baumgartner, R., 2011. Critical perspectives of sustainable development research and practice. Journal of Cleaner Production 19, 783-786.

Beal, C., Stewart, R., Huang, T., Rey, E., 2011. SEQ residential end use study. Australian Water Association Journal, 38(1), 80-84.

Blokker, E., Vreeburg, J., van Dijk, J., 2010. Simulating residential water demand with a stochastic end-use model. Journal of Water Resources, Planning and Management, 136(1), 19-26.

Chang, H., Parandvash, G. and Shandas, V., 2010. Spatial variations of single-family residential water conusmption in Portland, Oregon. Urban Geography 31, 953-972.

Chu, J., Wang, C., Chen, J. and Wang, H. (2009) Agent-based residential water use behavior simulation and policy implications: a case study in Beijing City. Water Resources Management 23, 3267-3295.

Corral-Verdugo, V., Frias-Armenta, M., Perez-Urias, F., Orduna-Cabrera, V. and EspinozaGallego, N., 2002. Residential water consumption, motivation for conserving water and the continuing Tragedy of the Commons. Environmental Management 30, 527-535.

Corral-Verdugo, V., Frías-Armenta, M., 2006. Personal normative beliefs, antisocial behavior, and residential water conservation. Environment and Behavior 38(3), 406-421

De Oliver, M., 1999. Attitudes and inaction - a case study of the manifest demographics of urban water conservation. Environment and Behavior 31(3), 372-394.

DeOreo W, Heaney J, Mayer P., 1996. Flow trace analysis to assess water use. American Water Works Association Journal, 88(1):79-90.

Dolnicar, S., Hurlimann, A., 2010. Australian water conservation behaviours and attitudes [online]. Australian Journal of Water Resources, 14, 43-53.

Domènech, L., Saurí, D., 2011. A comparative appraisal of the use of rainwater harvesting in single and multi-family buildings of the Metropolitan Area of Barcelona (Spain): social experience, drinking water savings and economic costs. J. Clean. Prod. 19, 598-608. 
Druckman, A., Sinclair, P. and Jackson, T., 2008. A geographically and socio-economically disaggregated local household consumption model for the UK. Journal of Cleaner Production $16,870-880$.

Farrelly, M., Brown, R., 2011. Rethinking urban water management: Experimentation as a way forward? Global Environmental Change 847, dio:10.1016/j.gloenvcha.2011.1001.1007.

Festinger, L., 1957. A theory of cognitive dissonance, Stanford University Press, Stanford, CA, USA.

Fidar, A., Memon, F. and Butler, D., 2010. Environmental implications of water efficient microcomponents in residential buildings. Science of the Total Environment 408, 5828-5835.

Fielding, KS., Louis, WR., Warren, C., Thompson., 2009. Environmental sustainability in residential housing: understanding attitudes and behaviour towards waster, water and energy consumption among Australian households. Australian Housing and Urban Research Institute Queensland Research Centre, AHURI Position Paper No. 121.

Gardner, G. T., Stern, P.C., 1996. Environmental Problems and Human Behavior, Allyn and Bacon, Boston, Mass, USA.

Geyer-Allely, E. and Zacarias-Farah, A., 2003. Policies and instruments fo promoting sustainable household consumption. Journal of Cleaner Production 11, 923-926.

Gregory, G., Di Leo, M., 2003. Repeated behavior and environmental psychology: the role of personal involvement and habit formation in explaining water consumption. Applied Social Psychology 33(6), 1261-1296.

Hamilton, L., 1985. Self-reported and actual savings in a water conservation campaign. Environment and Behavior 17(3), 315-326.

Heinrich, M., 2008. Water use in Auckland households. Auckland, NZ: Branz Ltd and WaterCare Services Lt, p. 1-118.

Inman, D., Jeffrey, P., 2006. A review of residential demand-side management tool performance and influences on implementation effectiveness. Urban Water Journal 3(3), 127143.

Jones, N., Evangelinos, K., Gaganis, P. and Polyzou, E., 2010. Citizen's perceptions on water conservation policies and the role of social capital. Water Resources Management 25, 509522.

Jorgensen, B., Graymore, M. and O'Toole, K., 2009. Household water use behavior: an integrated model. Journal of Environmental Management 91, 227-236.

Juárez-Nájera, M., Rivera-Martinez, J., Hafkamp, W., 2010. An explorative sociophyscological model for determining sustainable behavior: Pilot study in Germany and Mexican Universities. Cleaner Production 18, 686-694.

Kappel, K. and Grechenig, T., 2009. "Show-me": water consumption at a glance to promote water conservation in the shower, In Conference Proceedings of 'Persuasive 09', April 26-29, Claremont, California, USA.

Kantola, S.J., Syme, G.J., Campbell, N.A., 1984. Cognitive dissonance and energy conservation. Journal of Applied Psychology 69(3), 416-421.

Kennedy, A., 2010. Using Community-Based Social Marketing Techniques to Enhance Environmental Regulation. Sustainability, 2(4), 1138-1160 
Kenney, DS, Goemans, C, Klein, RA, Lowrey, J, Reidy, K., 2008. Residential water demand management: lessons from Aurora, Colorado. Journal of the American Water resources Association, 44 (1):192-207.

Keselman, H., Huberty, C., Lix, L., Olejnik, S., Cribbie, R., Donahue, B., Kowalchuk, R., Lowman, L., Petoskey, M., Keselman, J. and Levin, J., 1998. Statistical practices of educational researchers: an analysis of their ANOVA, MANOVA, and ANCOVA analyses. Review of Educational Research 68(3), 350-386.

Kraus, S.J., 1995. Attitudes and the prediction of behaviour: A meta-analysis of the empirical literature. Personal and Social Psychology Bulletin 2: 58-75.

Loh, M., Coghlan, P., 2003. Domestic water use study in Perth, Western Australia 1998 to 2000. Water Corporation of Western Australia

Mayer, P., DeOreo, W., Towler, E., Martien, L. and Lewis, D. (2004) Tampa Water Department Residential water conservation study. The impacts of high efficiency plumbing fixture retrofits in single family homes, Tampa Water Department and The United States Environmental Protection Agency.

Mayer, P., DeOreo, W., Opitz, E., Kiefer, J., Davis, W., Dziegielewski, B., Nelson, J. 1998. Residential end uses of water. Am. Water Works Assoc. Res. Found., Denver, Co.

Millock, K., Nauges, C., 2010. Household adoption of water-efficient equipment: the role of socio-economic factors, environmental attitudes and policy. Environmental Resource Economics, 46, 539-565.

Nieswiadomy, M., 1992. Estimating urban residential water demand: effects of price structure, conservation, and education. Water Resources Research 28(3), 609-615.

O'Toole, J., Sinclair, M., Leder, K., 2009. Collecting household water usage data: telephone questionnaire or diary? BMC Medical Research Methodology, 9, 72-83.

Olmstead, S., Stavins, R., 2009. Comparing price and nonprice approaches to urban water conservation. Water Resources Research, 45(W04301), doi:10.1029/2008WR007227.

QWC, 2010. South East Queensland Water Strategy, July 2010, The State of Queensland (Queensland Water Commission).

Renwick, M., Archibald, S., 1998. Demand side management policies for residential water use: who bears the conservation burden? Land Economics 74(3), 343-359.

Ridoutt, B. and Pfister, S., 2010. A revised approach to water footprinting to make transparent the impacts of consumption and production on global freshwater scarcity. Global Environmental Change 20, 113-120.

Roberts, P., 2004. Residential End Use Measurement Study. Yarra Valley Water 2005.

Russell, S., Fielding, K., 2010. Water demand management research: A psychological perspective, Water Resources Research, 46, W05302, doi10.1029/2009WR008408.

Spinks, A., Fielding, K., Russell, S., Mankad, A., Price, J., (forthcoming). Water demand management study: Baseline survey of household water use (Part A). Urban Water Security Research Alliance.

Stewart, R., Willis, R., Giurco, D., Panuwatwanich, K., Capati, G., 2010. Web based knowledge management system: linking smart metering to the future of urban water planning. Australian Planner, 47(2), 66-74. 
Stewart. R.A., Willis, R., Panuwatwanich, K. Sahin, O., (2011) Showering behavioural response to alarming visual display monitors: Longitudinal mixed method study. Behaviour \& Information Technology, i-First Article, DOI: 10.1080/0144929X.2011.577195].

Stamminger, R., 2011. Modelling resource consumption for laundry and dish treatment in individual households for various consumer segments. Energy Efficiency DOI: 10.1007/s12053-011-9114-X.

Stoeglehner, G., Edwards, P., Daniels, P. and Narodoslawsky, M., 2011. The water supply footprint (WSF): a strategic planning tool for sustainable regional and local water supplies. Journal of Cleaner Production, doi:10.1016/j.jclepro.2011.05.020.

Syme, G., Nancarrow, B., Seligman, C., 2000. The evaluation of information campaigns to promote voluntary household water conservation. Evaluation Review, 24(6), 539-578.

Syme, G., Seligman, C. and Thomas, J., 1990-1991. Predicting water consumption from homeowners' attitudes. Journal of Environmental Systems 20(2), 157-168.

Turner, A., Fyfe, J., Retamal, M., White, S., Coates, A., 2009. The one to one water savings program unpacking residential high water usage. IWA Efficient 09 Conference, Sydney, October 2009.

van Vugt, M., 2001. Community identification moderating the impact of financial incentives in a natural social dilemma: water conservation. Personality and Social Psychology Bulletin 27(11), 1440-1449.

Water Corporation, 2011. Perth residential water use study 2008/2009, Water Forever, Water Coporation, Western Australia.

Willis, R., Stewart, R.A., Talebpour, M.R., Mousavinejad, A, Jones, S., Giurco, D., 2009. Revealing the impact of socio-demographic factors and efficient devices on end use water consumption: case of Gold Coast Australia. In Proceedings of the 5th IWA Specialist Conference 'Efficient 2009', Sydney, Australia

Willis R, Stewart R, Panuwatwanich K, Jones S, A K., 2010a. Alarming visual display monitors affecting shower end use water and energy conservation in Australian residential households. Resources, Conservation and Recycling. Vol. 54, pp. 1117 - 1127, 2010:10.1016/j.resconrec.2010.03.004.

Willis, R.M., Stewart, R.A., Emmonds, S., (2010b) Pimpama-Coomera dual reticulation end use study: pre-commission baseline, context and post-commission end use prediction. Water, Science and Technology: Water Supply, 10(3), 302-314, doi: 10.2166/ws.2010.104.

Willis, R., Stewart, R., Giurco, D., Talebpour, M., Mousavinejad A., 2011. End use water consumption in households: impact of socio-demographic factors and efficient devices. Journal of Cleaner Production, in review.

Willis, R.M., Stewart, R.A., Panuwatwanich, K., Williams, P., Hollingsworth, A., 2011a. Quantifying the influence of environmental and water conservation attitudes on household end use water consumption. Journal of Environmental Management, 92(8), 1996-2008. , doi:10.1016/j.jenvman.2011.03.023

Willis, R.M., Stewart, R.A., Williams, P.R., Hacker, C.H., Emmonds, S.C., Capati, G., 2011b. Residential potable and recycled water end uses in a dual reticulated supply system. Desalination, 273(1-3), 201-211. doi: 10.1016/j.desal.2011.01.022.

White, S., and Fane, S., 2002. Designing cost effective water demand management programs in Australia. Water Science and Technology 46(6/7), 225-232. 
Wutich, A., 2009. Estimating household water use: a comparison of diary, prompted recall and free recall methods. Field Methods 21(1):49-6. 


\section{TABLES}

\section{Table 1. Characteristics of self-reporting groups}

\begin{tabular}{|c|c|c|c|c|c|c|}
\hline \multirow{2}{*}{ Characteristic } & \multirow{2}{*}{$\begin{array}{l}\text { Descriptor } \\
\text { (values are all means) }\end{array}$} & \multicolumn{3}{|c|}{ Self-reported water use category ${ }^{\mathrm{A}, \mathrm{B}}$} & \multirow[t]{2}{*}{$\mathrm{df}^{\mathrm{C}}$} & \multirow{2}{*}{$\begin{array}{l}\mathrm{F} \\
\text { value }\end{array}$} \\
\hline & & $\begin{array}{l}\text { High } \\
\text { (av.=301) }\end{array}$ & $\begin{array}{l}\text { Medium } \\
\text { (av.=452) }\end{array}$ & $\begin{array}{l}\text { Low } \\
(\text { av.=407) }\end{array}$ & & \\
\hline \multirow[t]{3}{*}{ Respondent } & Age of respondent & $57_{a}(13.7)$ & $47_{\mathrm{a}}(12.8)$ & $51_{\mathrm{ab}}(14)$ & 2,201 & $11.51 * * *$ \\
\hline & $\begin{array}{l}\text { Education ratio } \\
\text { (\%Secondary:\%TAFE/trade:\%Tertiary) }\end{array}$ & $36: 29: 35$ & $29: 26: 45$ & $29: 24: 47$ & - & - \\
\hline & Gender ratio (\%male:\%female) & $46: 54$ & $42: 58$ & 43:57 & - & - \\
\hline \multirow{5}{*}{$\begin{array}{l}\text { Household } \\
\text { socio- } \\
\text { demographics }\end{array}$} & People per house & $2.3_{\mathrm{a}}(1.0)$ & $3.1_{\mathrm{b}}(1.3)$ & $2.9_{\mathrm{ab}}(1.1)$ & 2,216 & $12.48^{* * *}$ \\
\hline & Number of children & $0.30_{\mathrm{a}}(.70)$ & $0.77_{\mathrm{b}}(1.0)$ & $0.50_{\mathrm{ab}}(.09)$ & 2,214 & $7.41 * * *$ \\
\hline & Children $\leq 3$ years old & $0.07_{\mathrm{a}}(.25)$ & $0.24_{\mathrm{b}}(.49)$ & $0.23 \mathrm{ab}(.59)$ & 2,216 & $4.38 *$ \\
\hline & Percentage teenagers (\%) & 14 & 30 & 24 & - & - \\
\hline & Income $^{\mathrm{D}}$ & $57.1_{\mathrm{a}}(7.3)$ & $79.4_{\mathrm{b}}(7.8)$ & $89_{\mathrm{b}}(21)$ & 2,201 & $9.72 * * *$ \\
\hline
\end{tabular}

\footnotetext{
${ }^{A}$ Note. ${ }^{*} \mathrm{p}<.05,{ }^{* * *} \mathrm{p}<.001$; Means with different subscripts are significantly different from each other. The standard deviations are italicised in parentheses.

${ }^{B}$ The actual average household water use for each group is reported in $\mathrm{L} / \mathrm{hh} / \mathrm{d}$ in parentheses.

${ }^{\mathrm{C}} \mathrm{df}=$ degrees of freedom between and within groups.

${ }^{\mathrm{D}}$ Estimated from taking the average of the household income category that each respondents selected (Gregory and Di Leo 2003), where categories were: $1=<\$ 30,000,2=\$ 30,000-\$ 59,000,3=\$ 60,000-\$ 89,999,4=\$ 90,000-\$ 119,999,5=\$ 120,000-\$ 149,999,6 \geq$ $\$ 150,000$
} 
Table 2. Comparison of high, medium, and low water user groups on psycho-social questions

\begin{tabular}{|c|c|c|c|c|c|c|}
\hline \multirow[t]{2}{*}{ ID } & \multirow[t]{2}{*}{ Household water use survey question } & \multirow[t]{2}{*}{$d f^{\beta}$} & \multicolumn{3}{|c|}{ Mean $^{\mathbf{A}}$} & \multirow[t]{2}{*}{ F value $^{\mathrm{C}}$} \\
\hline & & & High & Med & Low & \\
\hline Q3a & $\begin{array}{l}\text { "It is expected of me that I save water } \\
\text { around the house and garden" }\end{array}$ & 2,182 & 6.4 & 6.28 & 6.00 & 0.061 \\
\hline Q3d & $\begin{array}{l}\text { "I feel a strong personal obligation to } \\
\text { save water around the house and } \\
\text { garden }\end{array}$ & 2,187 & $6.4_{a}$ & $6.4_{a}$ & $5.67_{b}$ & $4.236^{*}$ \\
\hline Q3f & $\begin{array}{l}\text { "I would feel guilty if I didn’t save } \\
\text { water around the garden" }\end{array}$ & 2, 185 & 6.09 & 5.97 & 6.00 & 0.395 \\
\hline Q9c & $\begin{array}{l}\text { "In the last } 6 \text { months how often did } \\
\text { you have shorter showers?" }\end{array}$ & 2,186 & $4.37 \mathbf{a}$ & $3.82_{\mathbf{b}}$ & $4.22_{\mathrm{ab}}$ & $8.499 * * *$ \\
\hline Q9d & $\begin{array}{l}\text { "In the last } 6 \text { months how often did } \\
\text { you only run the washing machine if } \\
\text { it is full?" }\end{array}$ & 2,186 & 4.60 & 4.41 & 4.30 & 2.216 \\
\hline Q9h & $\begin{array}{l}\text { "In the last } 6 \text { months how often did } \\
\text { you use minimal water in the } \\
\text { kitchen?" }\end{array}$ & 2,187 & $4.45_{a}$ & $4.31_{\mathbf{a b}}$ & $3.78_{b}$ & $3.434 *$ \\
\hline Q9k & $\begin{array}{l}\text { "In the last } 6 \text { months how often did } \\
\text { you turn the taps off to brush your } \\
\text { teeth?” }\end{array}$ & 2,186 & 4.67 & 4.43 & 4.33 & 2.889 \\
\hline Q12a & $\begin{array}{l}\text { "It is expected of me that I should } \\
\text { install water efficient appliances" }\end{array}$ & 2,186 & 5.81 & 5.42 & 4.89 & $3.557^{*}$ \\
\hline Q23 & Self-identity as a water conserver & 2,187 & $6.15^{\mathrm{A}}$ & $5.85^{\mathrm{B}}$ & $5.77^{\mathrm{AB}}$ & $4.269^{*}$ \\
\hline Q24g & $\begin{array}{l}\text { "We think of ourselves as a water } \\
\text { conserving household" }\end{array}$ & 2,163 & $6.16^{\mathrm{A}}$ & $5.62^{\mathrm{B}}$ & $5.33^{\mathrm{B}}$ & $13.34^{* * *}$ \\
\hline Q24h & $\begin{array}{l}\text { "Water conservation is important in } \\
\text { our household" }\end{array}$ & 2,165 & $6.08^{\mathrm{A}}$ & $5.77^{\mathrm{B}}$ & $5.67^{\mathrm{AB}}$ & 3.325* \\
\hline
\end{tabular}

\footnotetext{
A Note. ${ }^{*} \mathrm{p}<.05,{ }^{* * *} \mathrm{p}<.001$; Means with different subscripts are significantly different from each other. The standard deviations are italicised in parentheses.

${ }^{\mathrm{B}} d f=$ degrees of freedom between and within groups.
} 
Table 3. Information on water accounts for study regions.

\begin{tabular}{lll}
\hline $\begin{array}{l}\text { Degree of } \\
\text { information }\end{array}$ & Region within study sample & $\begin{array}{l}\text { Water consumption data information provided on } \\
\text { water account (all in L/hh/d) }\end{array}$ \\
\hline Standard & $\begin{array}{l}\text { Gold Coast, Ipswich, Sunshine } \\
\text { Coast }\end{array}$ & $\begin{array}{l}\text { Same period last year, previous period, current } \\
\text { period }\end{array}$ \\
High & Brisbane & $\begin{array}{l}\text { Same period last year, previous period, current } \\
\text { period, your water consumption, your local average, } \\
\text { Brisbane average }\end{array}$ \\
\hline
\end{tabular}




\section{FIGURES}

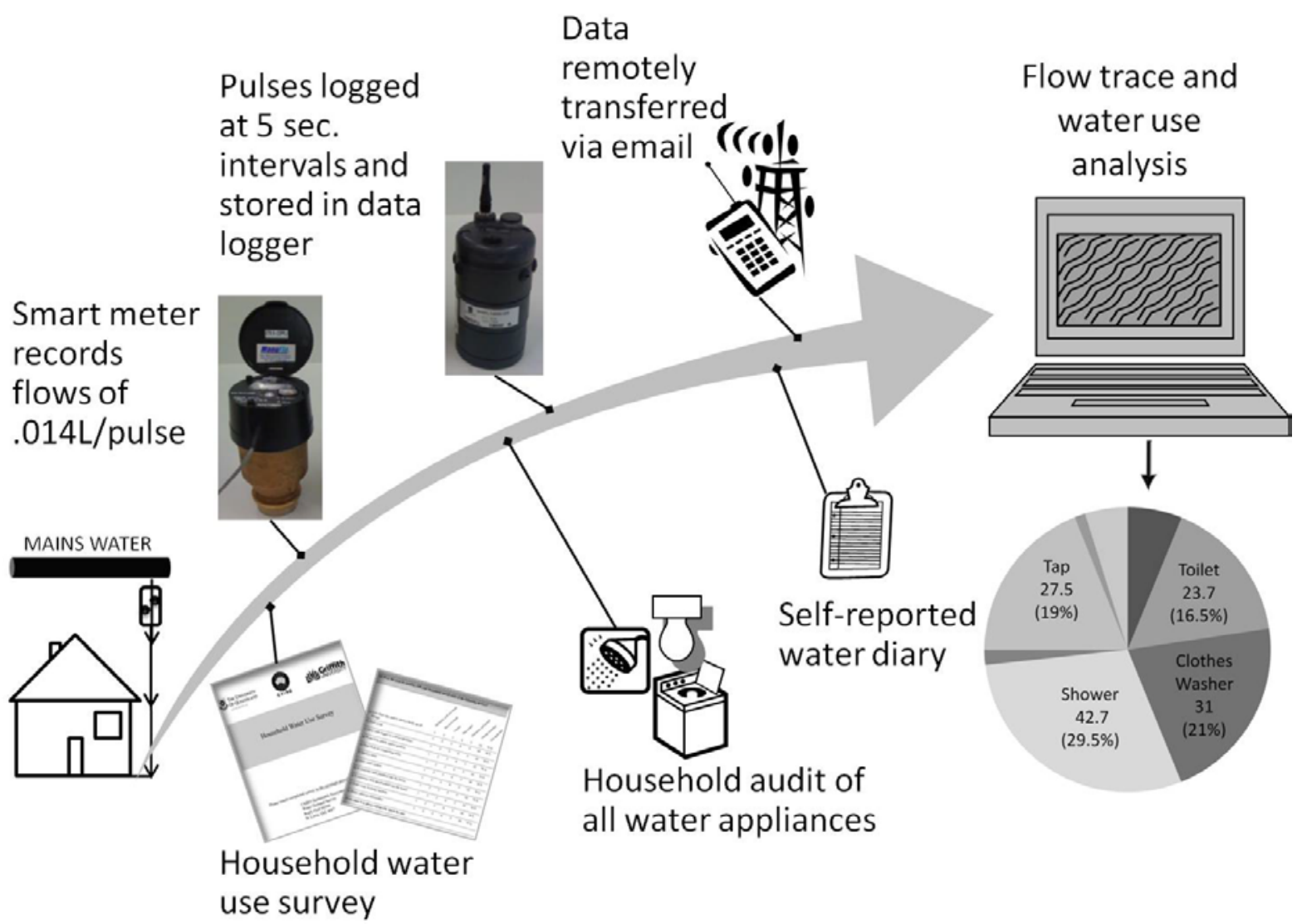

Figure 1. Schematic flow of mixed method process for acquisition, capture, transfer and analysis of water flow data. 


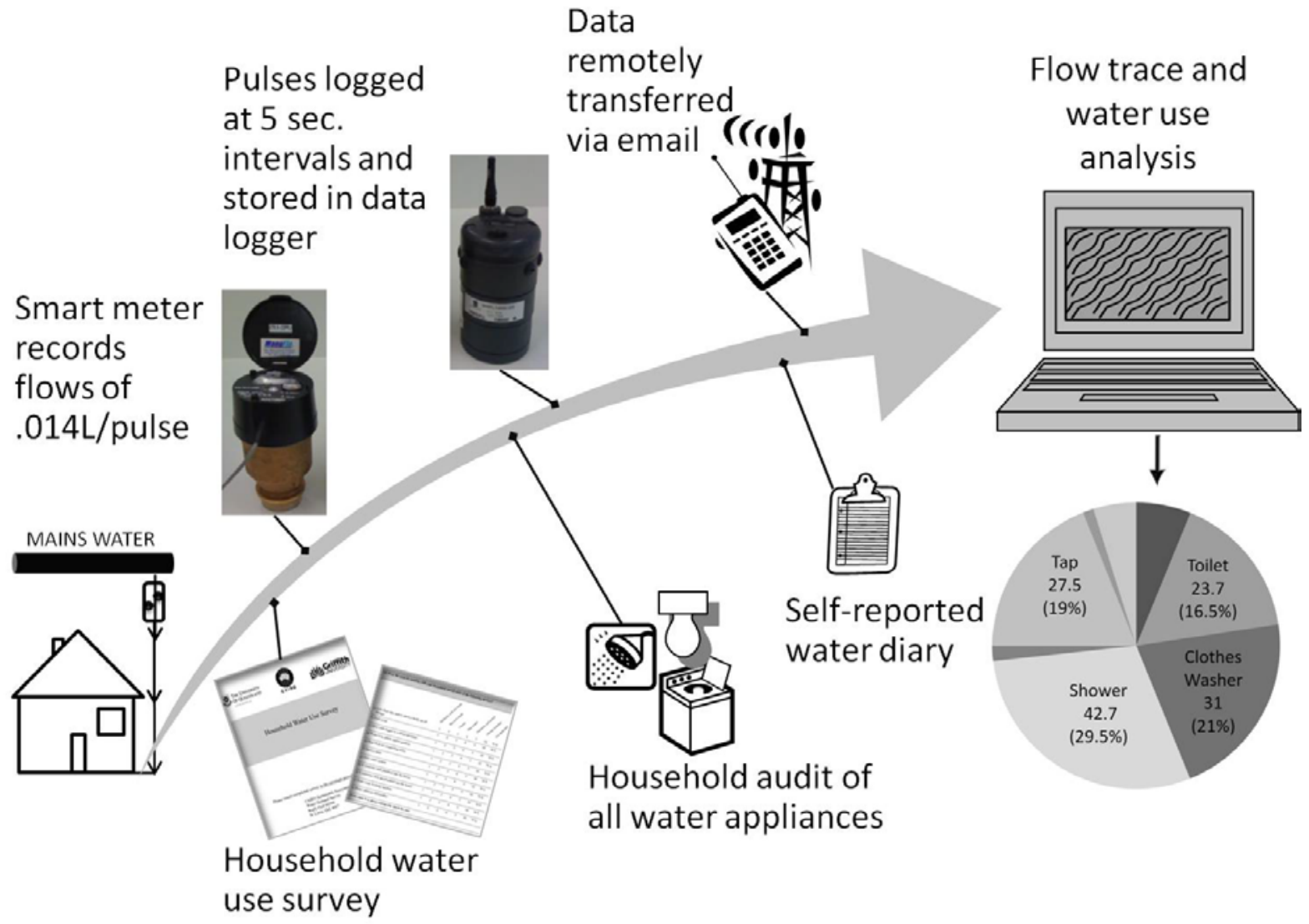

Figure 1. Schematic flow of mixed method process for acquisition, capture, transfer and analysis of water flow data. 


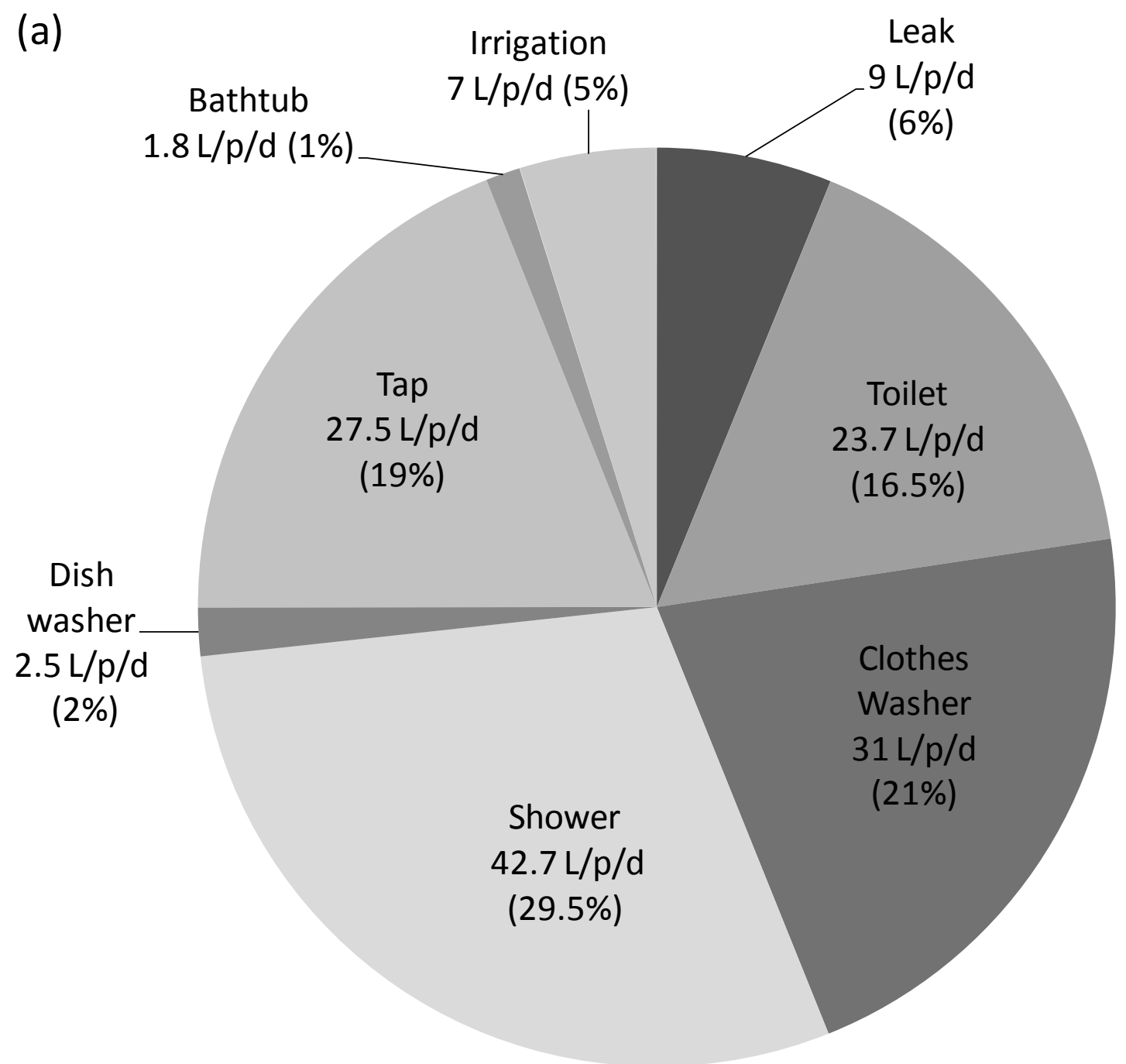

Total average $=145.3 \mathrm{~L} / \mathrm{p} / \mathrm{d}$ 


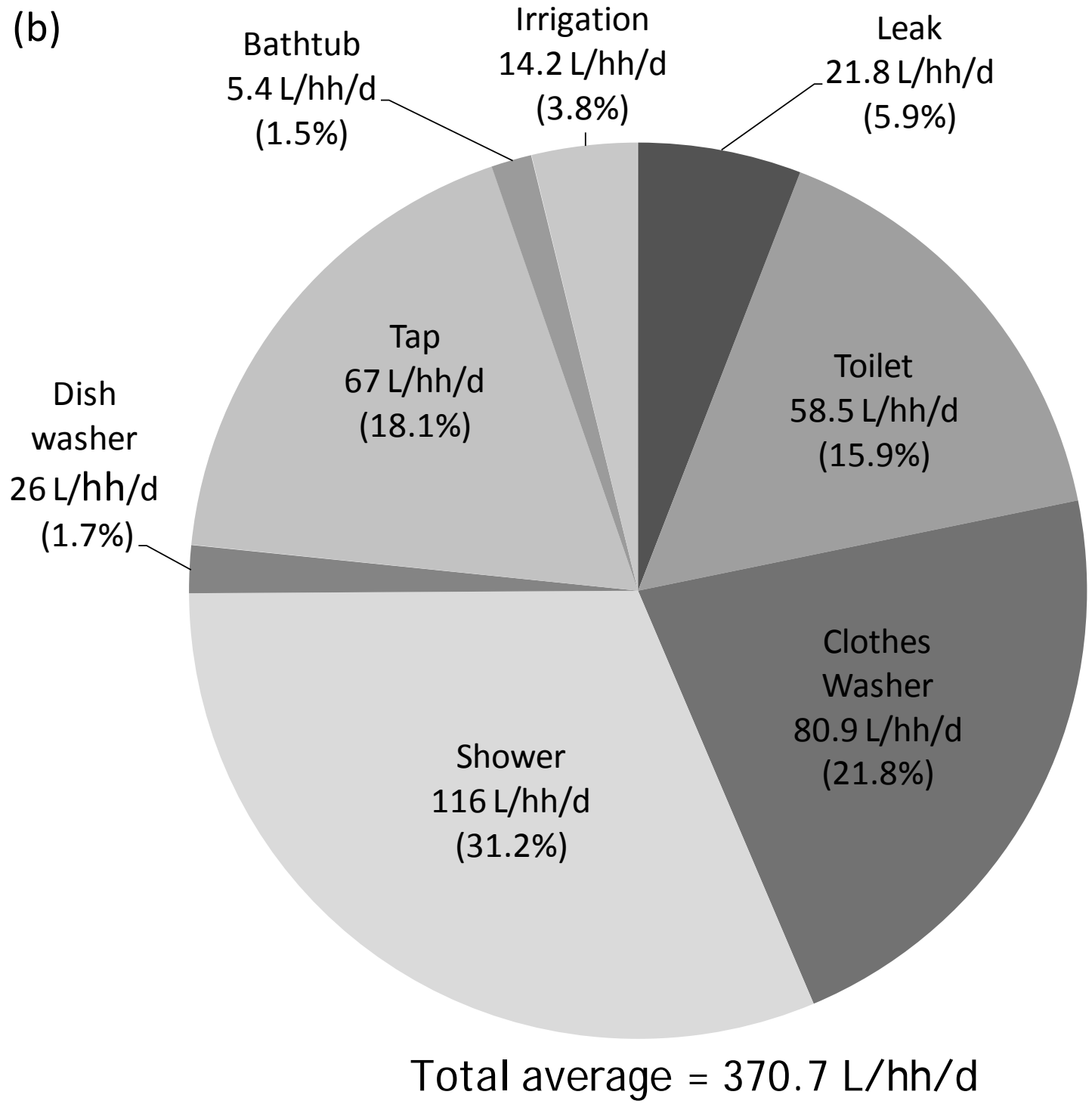

Figure 2 Results of household water consumption from the SEQREUS for (a) per capita daily water use and (b) per household daily water use 
(a)

\begin{tabular}{|c|c|c|c|c|}
\hline \multirow{2}{*}{ : 160} & \multicolumn{2}{|r|}{$\begin{array}{c}\text { Total } \\
156 \mathrm{~L} / \mathrm{p} / \mathrm{d}\end{array}$} & \multirow{2}{*}{$\begin{array}{c}\text { Total } \\
143 \mathrm{~L} / \mathrm{p} / \mathrm{d}\end{array}$} & \multirow[b]{2}{*}{$\begin{array}{c}\text { Total } \\
132 \mathrm{~L} / \mathrm{p} / \mathrm{d}\end{array}$} \\
\hline & $\begin{array}{c}\text { Total } \\
130 \mathrm{~L} / \mathrm{p} / \mathrm{d}\end{array}$ & & & \\
\hline 120 & & & & \\
\hline 100 & & & & \\
\hline 80 & & & & \\
\hline 60 & & & & \\
\hline 40 & & & & \\
\hline 20 & & & & \\
\hline & "High" & "Med" & "Low" & $\begin{array}{l}\text { "Don't } \\
\text { know" }\end{array}$ \\
\hline ation & 4.2 & 7.5 & 8.2 & 4.5 \\
\hline tub & 1.5 & 2.6 & 1.7 & 0.8 \\
\hline & 25.7 & 28.8 & 25.3 & 24.8 \\
\hline washer & 2.1 & 3.3 & 2.5 & 1.4 \\
\hline ver & $33.0^{\star \star \star}$ & 49.1 & 42.9 & 37.6 \\
\hline eswasher & $26.6^{\star *}$ & 34.3 & 34.8 & 24.1 \\
\hline II & 23.8 & 24.9 & 24.0 & 21.8 \\
\hline a & 13.2 & 6.4 & 3.2 & 17.8 \\
\hline
\end{tabular}


(b)

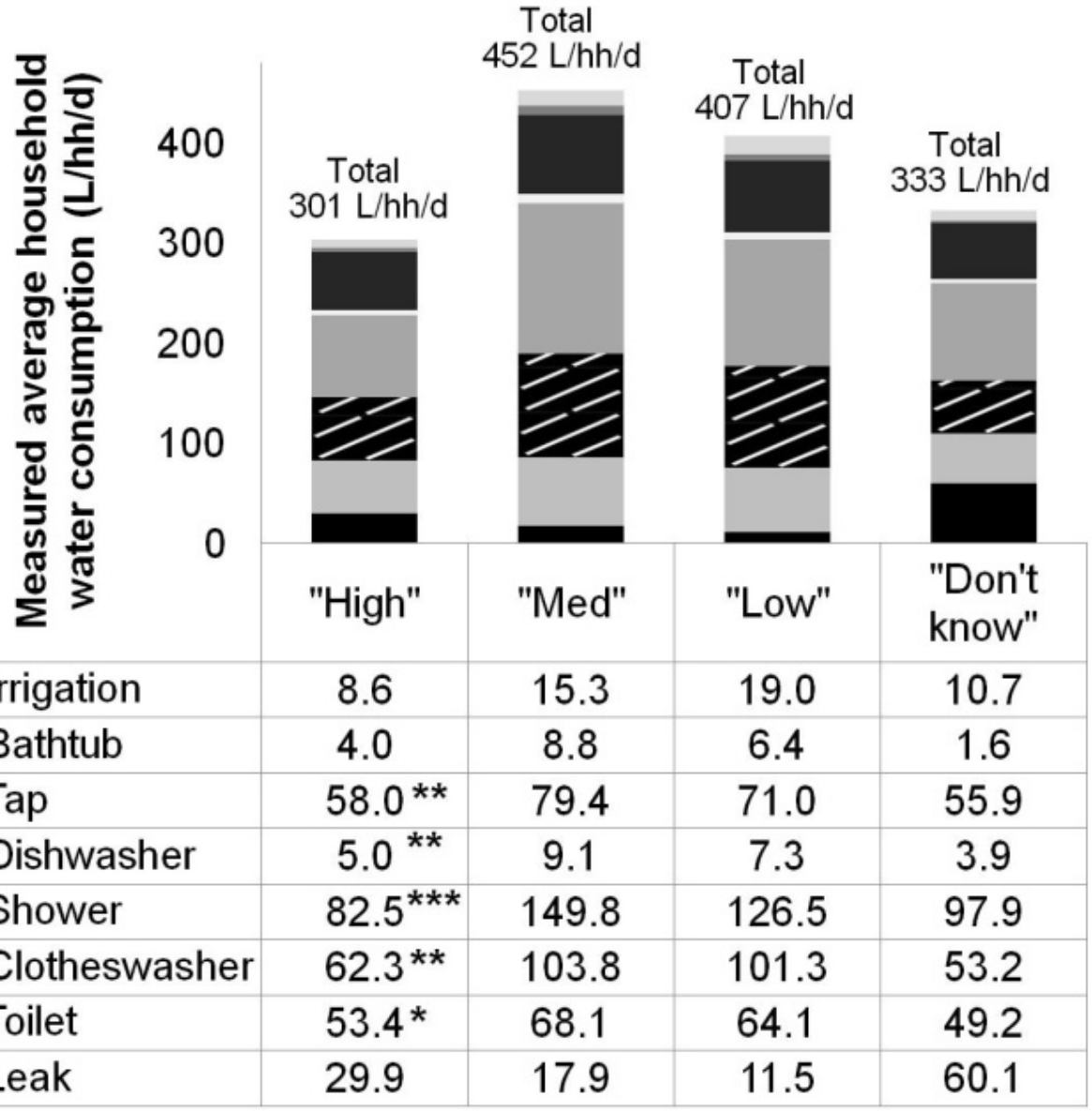

Figure 3 Comparisons of (a) per capita and (b) per household actual daily water use across self-reported water use groups. Note. ${ }^{*} \mathbf{p}<.05,{ }^{* *} \mathbf{p}<0.01{ }^{* * *} \mathbf{p}<.001$; Means with different subscripts are significantly different from each other. 


\begin{tabular}{|c|c|c|c|c|c|c|c|c|c|c|}
\hline \multirow{10}{*}{ 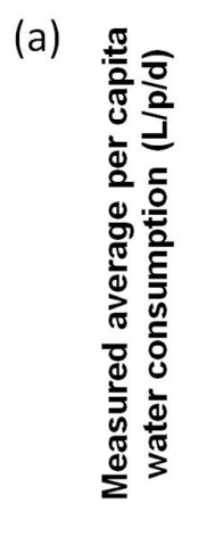 } & 180 & \multirow{8}{*}{$1 / 1$} & \multirow{8}{*}{$1 / 1$} & \multirow{8}{*}{$1 / 1$} & \multirow{8}{*}{$1 /$} & \multirow{8}{*}{$1 / 1$} & \multirow{8}{*}{$1 / 1$} & \multirow{8}{*}{$7 / 1$} & \multirow{8}{*}{$\mathrm{V}$} & \multirow{8}{*}{$1 / 1$} \\
\hline & 160 & & & & & & & & & \\
\hline & 140 & & & & & & & & & \\
\hline & 120 & & & & & & & & & \\
\hline & 100 & & & & & & & & & \\
\hline & 80 & & & & & & & & & \\
\hline & 60 & & & & & & & & & \\
\hline & $\begin{array}{l}40 \\
20\end{array}$ & & & & & & & & & \\
\hline & 0 & High & Med & J owe & Hiah & $\mathrm{Med}$ & J ow & Hiah & Med & J ow \\
\hline & & \multicolumn{3}{|c|}{ Secondary } & \multicolumn{3}{|c|}{ Trade / TAFE } & \multicolumn{3}{|c|}{ Tertiary } \\
\hline \multicolumn{2}{|l|}{ Irrigation } & 4.6 & 6.7 & 5.9 & 5.1 & 4.0 & 11.6 & 2.9 & 10.1 & 7.8 \\
\hline \multicolumn{2}{|l|}{ Bathtub } & 0.6 & 1.3 & 0.0 & 3.1 & 4.8 & 0.0 & 1.1 & 2.3 & 3.5 \\
\hline \multicolumn{2}{|l|}{ - Tap } & 25.1 & 25.5 & 25.6 & 25.4 & 27.9 & 22.7 & 25.8 & 30.6 & 26.4 \\
\hline \multicolumn{2}{|c|}{$\square$ Dishwasher } & 1.4 & 3.6 & 1.7 & 2.0 & 2.5 & 1.0 & 2.8 & 3.7 & 3.8 \\
\hline \multicolumn{2}{|c|}{ Shower } & 29.6 & 41.8 & 34.3 & 31.1 & 52.4 & 47.5 & 37.1 & 51.8 & 45.9 \\
\hline \multicolumn{2}{|c|}{ Clothes washer } & 24.0 & 29.8 & 28.2 & 28.6 & 41.7 & 40.3 & 27.0 & 32.8 & 36.0 \\
\hline \multicolumn{2}{|c|}{ - Toilet } & 21.7 & 23.7 & 28.4 & 21.9 & 25.5 & 25.7 & 27.1 & 23.0 & 20.6 \\
\hline \multicolumn{2}{|l|}{ - Leak } & 20.0 & 10.3 & 2.2 & 8.5 & 4.2 & 5.0 & 10.1 & 5.2 & 3.1 \\
\hline
\end{tabular}

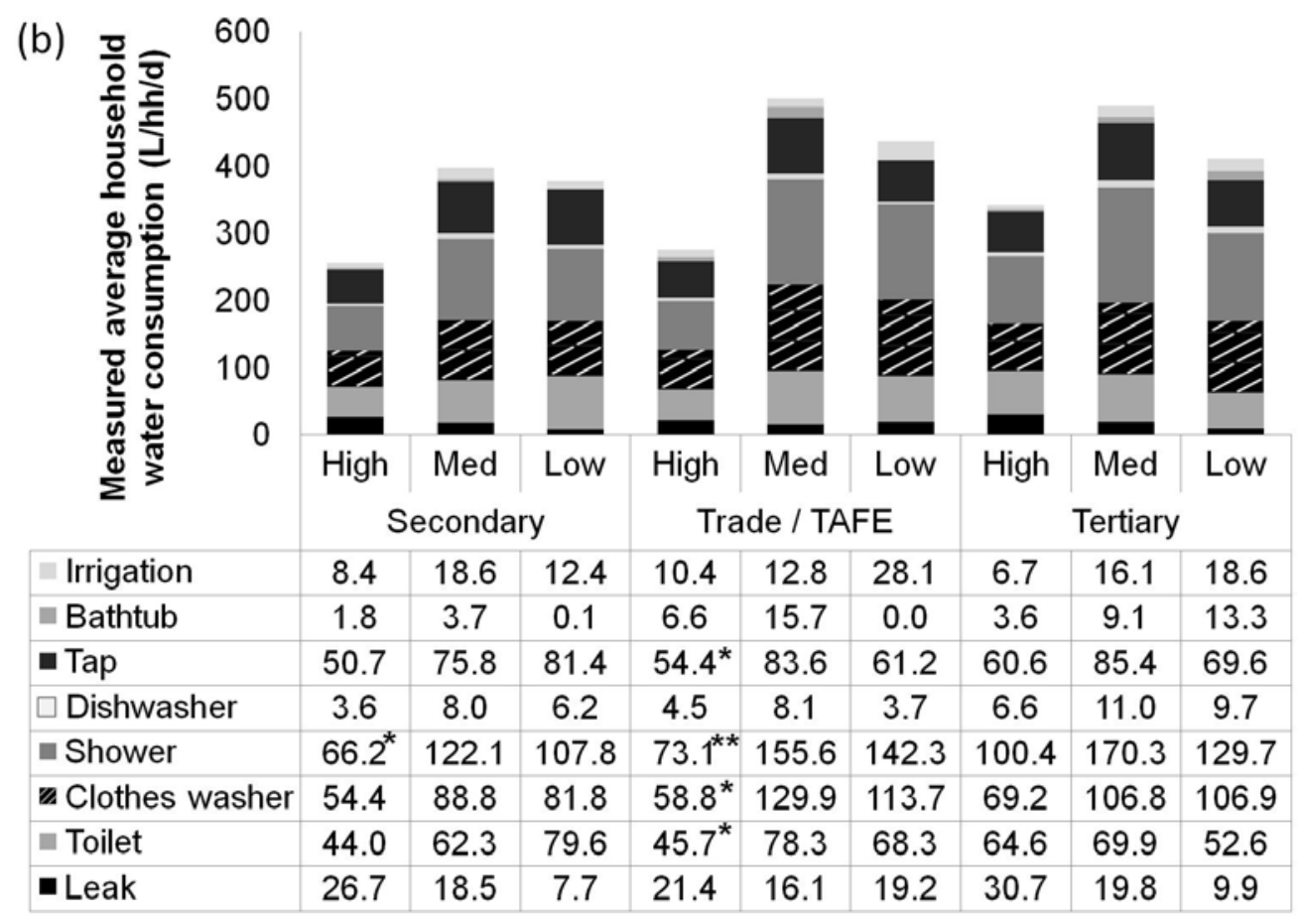

Figure 4. Comparisons of education with self-reported low, medium and high water users for (a) per capita use and (b) per household use. Note. ${ }^{*} \mathbf{p}<.05$, ${ }^{* *} \mathbf{p}<0.01$; Means with different subscripts are significantly different from each other. 


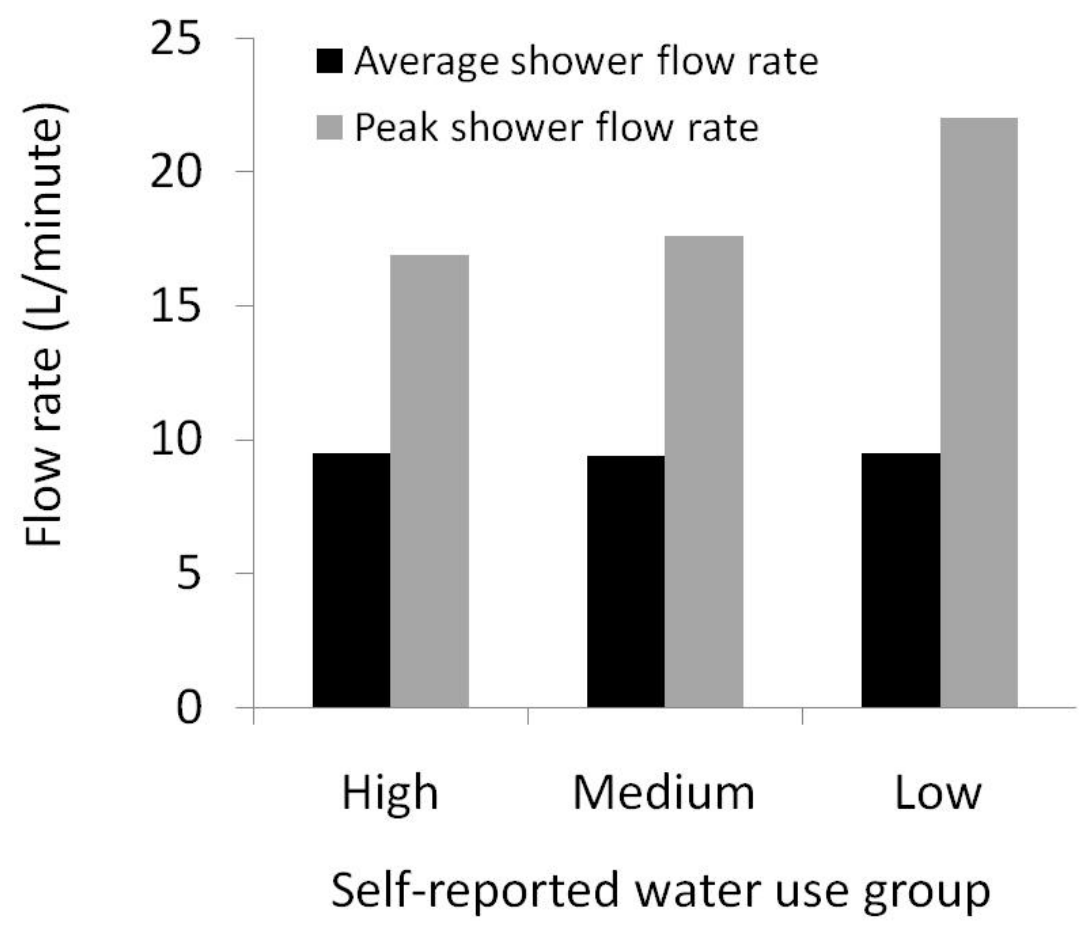

- Clothes washing machine star rating (LHS)

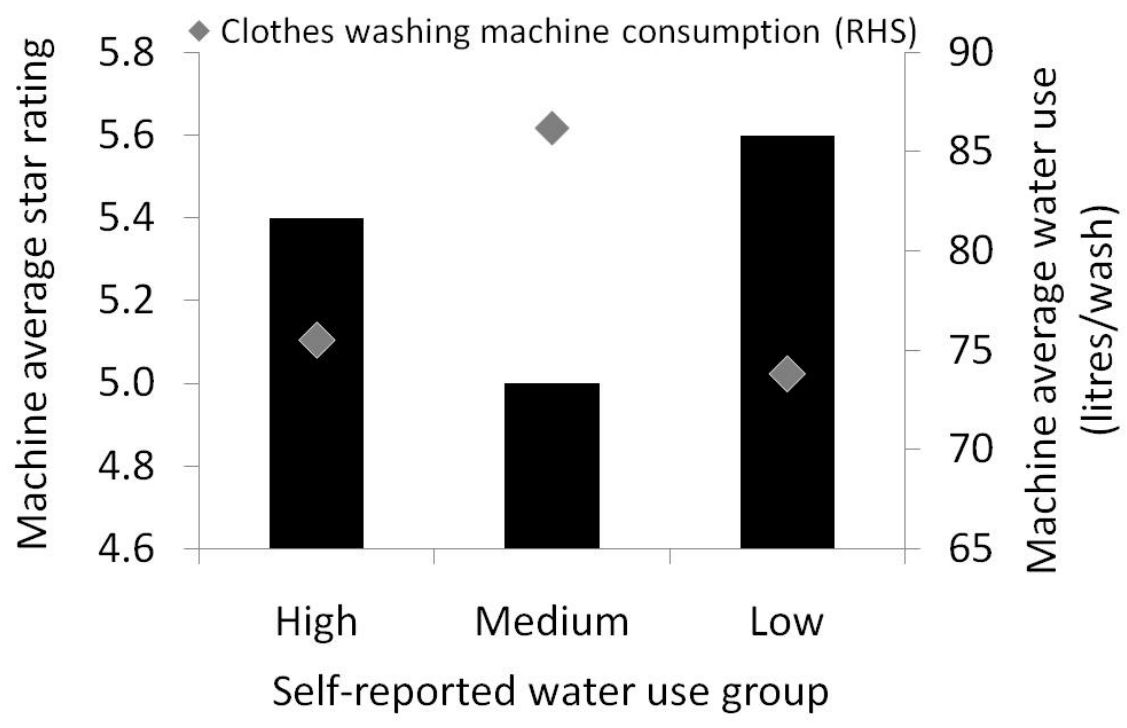

Figure 5. Characteristics of water efficient household stock: (a) shower head efficiency and (b) clothes washing machine efficiency, for the self-reported water use groups. 


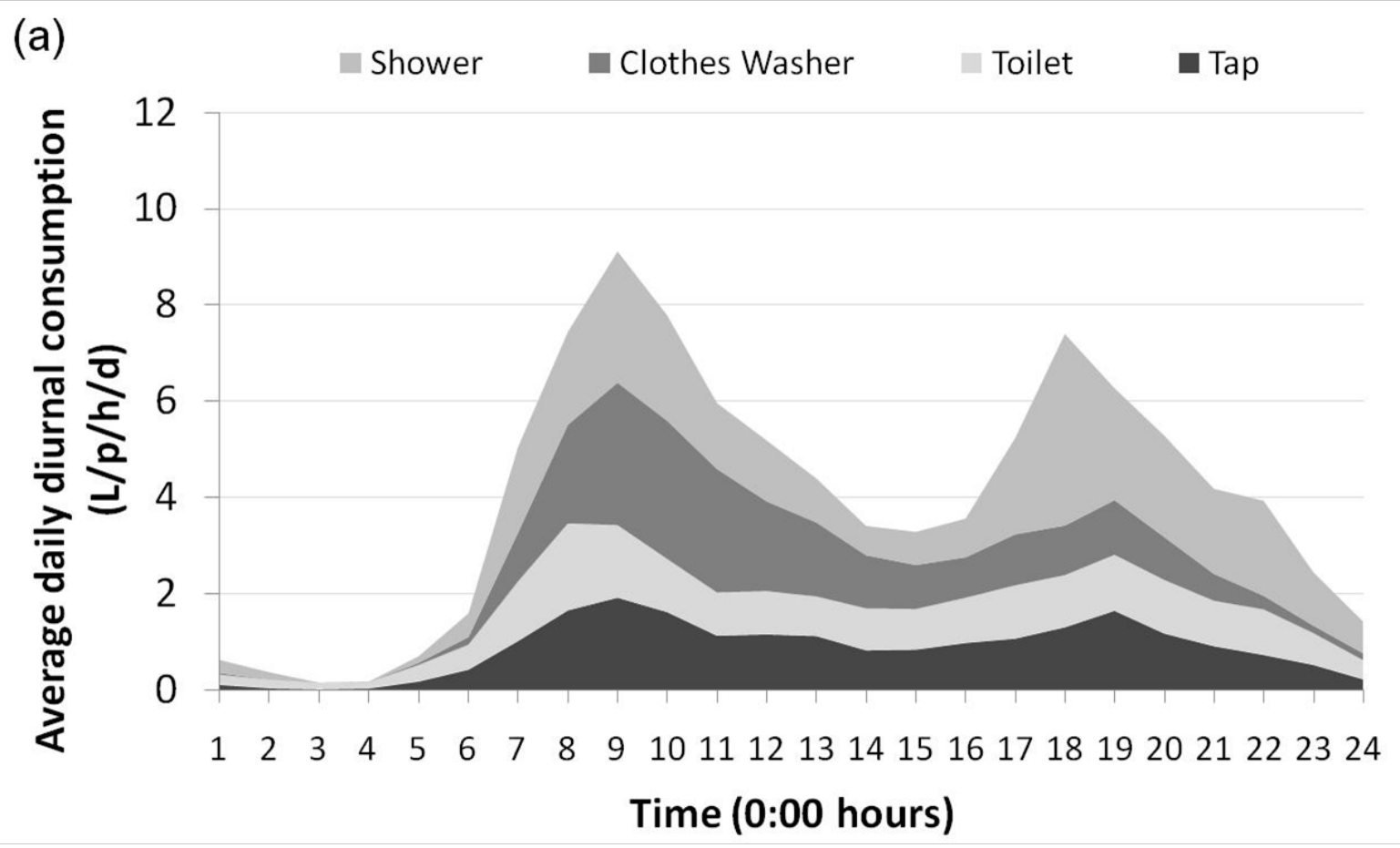

(b)

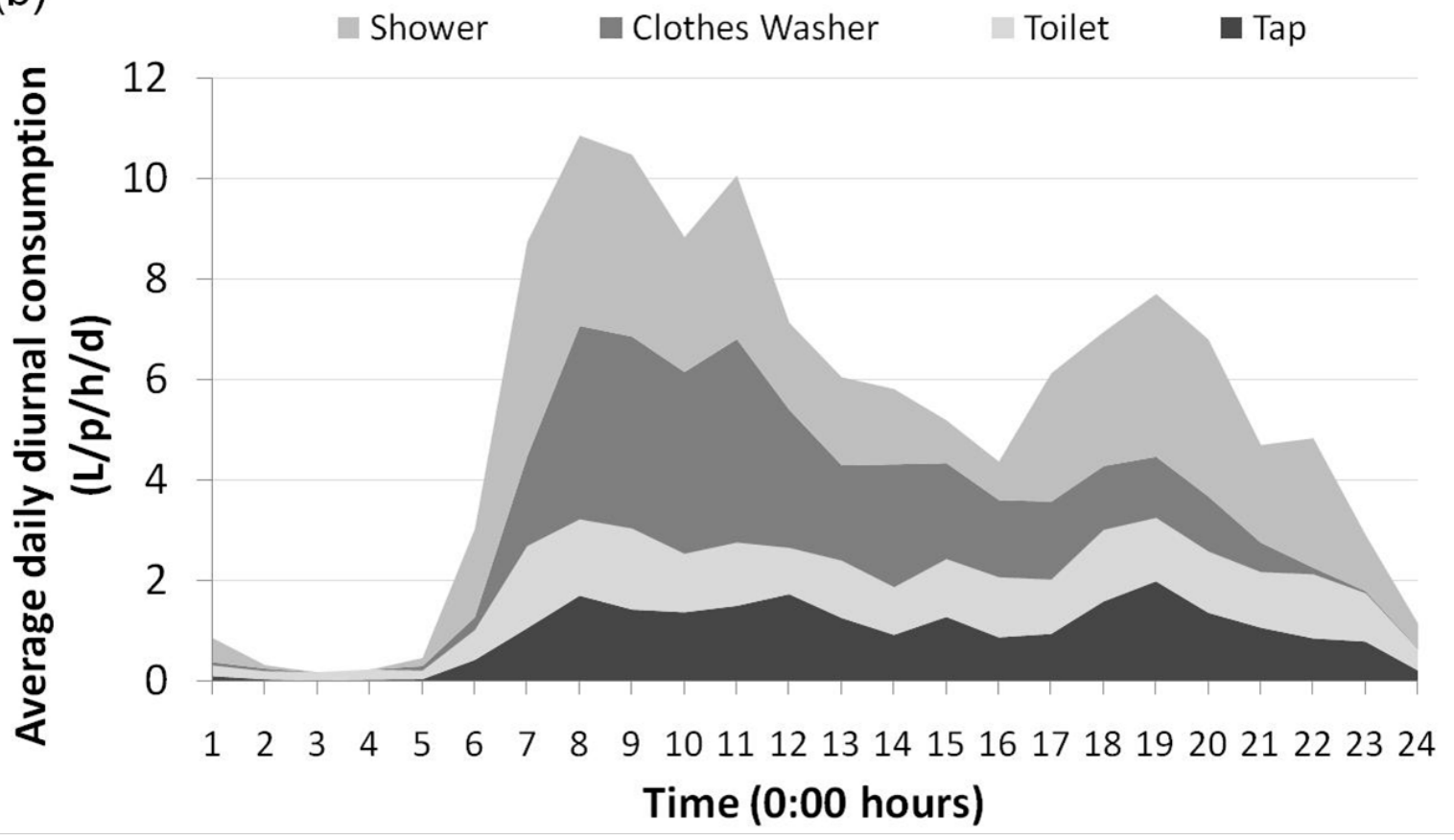




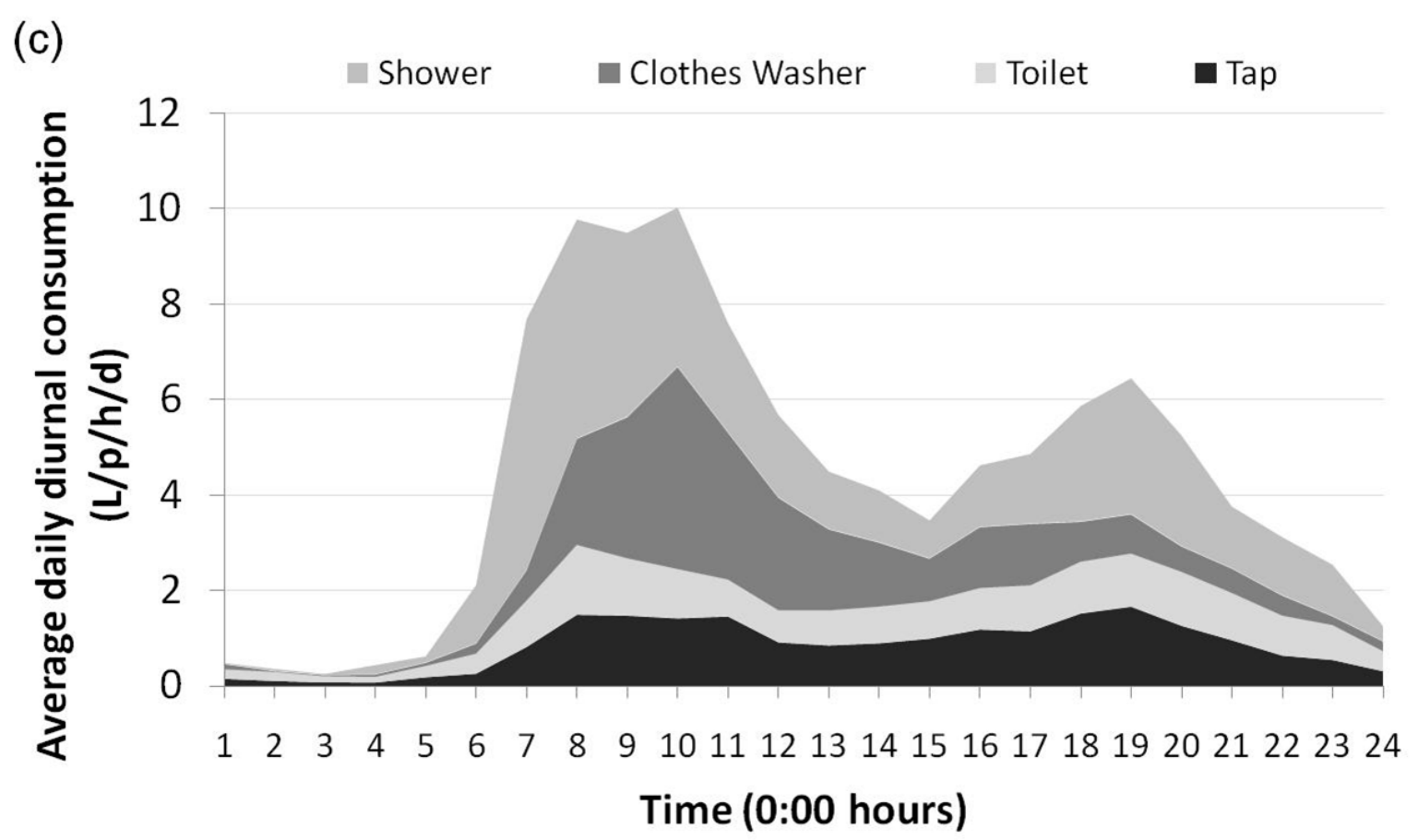

Figure 6. Average daily end use diurnal pattern analysis for self-reported (a) high, (b) medium and (c) low water users. 

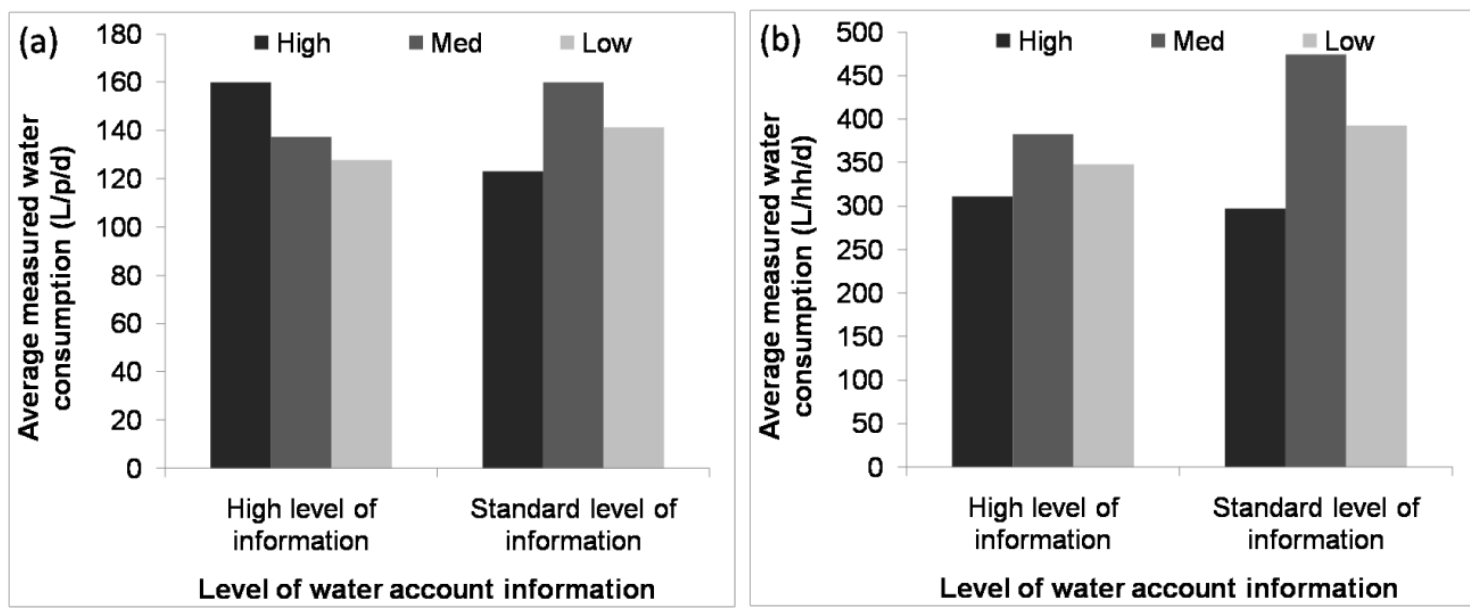

Figure 7. Billing notice information level relationship with (a) per capita and (b) per household self-reported water user groups. 